\title{
Voting and Peer Effects: Experimental Evidence from Mozambique
}

\author{
MARCEL FAFCHAMPS
}

Stanford University

ANA VAZ

University of Oxford

PEDRO C. VICENTE

Universidade Nova de Lisboa

\section{Introduction}

The rationality of voter turnout in political elections is often questioned: unless a person casts the deciding vote, voting has no effect on the outcome (e.g., Feddersen 2004). This is particularly true in elections where one contender has widespread support and the outcome is fairly certain. If no one votes, however, the electoral outcome is unlikely to reflect the preferences of the electorate. Not voting is therefore equivalent to free riding on other people's electoral participation. As a consequence, voting is often seen as a civic duty. Although some countries (e.g., Belgium, Brazil, Peru) make voting a legal obligation, most do not. The level of electoral participation therefore depends on the probability

We wish to thank Jenny Aker, Oriana Bandiera, Cátia Batista, Paul Collier, Eliana La Ferrara, Ted Miguel, Gerard Padro-i-Miquel, and Imran Rasul for helpful suggestions. Miguel Ferreira provided superb research assistance. We also wish to acknowledge useful comments by participants in seminars at the London School of Economics/University College of London, Stanford University, Université libre de Bruxelles, and the United Nations University-Maastricht Economic and Social Research Institute on Innovation and Technology, as well as by participants at conferences of Markets, Organizations and Votes in Economics; the Stanford Institute for Theoretical Economics; the Northeast Universities Development Consortium; and the North-American Winter Meeting of the Econometric Society. We are particularly grateful to @Verdade, Associação Moçambicana para o Desenvolvimento, Observatório Eleitoral, and Secretariado Técnico de Administração Eleitoral for fruitful collaboration. Adérito Caldeira, Sheikh Abdul Carimo, Erik Charas, Joshua Haynes, Thomas Kroner, Felisberto Naife, João Pereira, and Carlos Shenga offered crucial input, for which we are most thankful. Finally, we would like to express our gratitude for the fantastic work offered by supervisors Egídio Chaimite, Alberto da Cruz, Egídio Guambe, Aquílcia Samuel, and the group of enumerators with whom we worked: their dedication to this project was critical to its success. We wish to acknowledge financial support from the International Growth Centre and the Foundation Open Society Institute (Zug). Pedro C. Vicente is grateful for a grant from Trinity College Dublin. All errors are our own. Contact the corresponding author, Pedro C. Vicente, at pedro.vicente@novasbe.pt.

Electronically published December 16, 2019

(c) 2019 by The University of Chicago. All rights reserved. 0013-0079/2020/6802-0008\$10.00 
that voters attribute their own vote to being pivotal and on the social norms that are in place regarding voting. Peer influence may affect both.

The purpose of this paper is to study peer effects in political participation. A randomized control trial was organized in Mozambique to study the effect of voter education during the 2009 elections. The study of voter education in developing countries has seen recent attention, as electoral problems such as clientelism and vote buying (Wantchekon 2003; Fujiwara and Wantchekon 2013; Vicente 2014), violence (Collier and Vicente 2014), and low accountability (Banerjee et al. 2011) have been identified as affecting the likelihood that elections translate into public policies that produce broad-based development. In particular, since the first democratic elections in 1994, Mozambique has experienced a dramatic decrease in political participation that has accompanied the consolidation of the ruling party's power.

The voter education campaign we study was implemented in collaboration with a free newspaper and a consortium of local nongovernmental organizations (NGOs). Its main objective was to increase electoral participation. Three different treatments were administered nationwide across four provinces. The first is the distribution of the free newspaper, which focuses on neutral information about the elections. The second is a text-messaging hotline to which citizens can report electoral problems. The third is civic education delivered via a leaflet and text messages providing information about the elections. All treatments include an appeal for voter participation in the elections. Treatments were allocated randomly across locations. Within locations, a number of randomly selected individuals were directly targeted by the campaign. We refer to them as "targeted." We also follow a randomly selected number of individuals who reside in treated locations but are not directly targeted by the campaign. We refer to them as "untargeted." Targeted and untargeted individuals are always the head of household or the spouse of the household head.

Our focus is to estimate the within-village peer effects of the intervention. Following Fafchamps and Vicente (2013), we divide peer effects into reinforcement and diffusion effects. "Reinforcement" refers to the effect of the campaign for targeted individuals who are socially or geographically proximate to other sampled individuals. "Diffusion" refers to the effect of the treatment on untargeted individuals in treated locations who are close to targeted individuals. Aker, Collier, and Vicente (2017) studied the direct average treatment effect (ATE) of the voter education campaign we analyze in this paper. Their results are briefly summarized here to enable comparability with peer effects.

In terms of outcome variables, we exploit a rich individual data set that includes survey measures of individual turnout, a behavioral measure of political participation, and measures of information and interest in politics. We also 
report ATEs using official voting records at the polling station level. To estimate reinforcement and diffusion effects, we use detailed measures of social and geographic connectedness between individuals, including measures of chatting, kinship, and geographical distance between respondents' houses.

The intervention is found to increase voter turnout at the polling station level, as given by official records. Survey measurements show that turnout increases both among targeted and untargeted individuals. We also report a clear increase in information about the elections among targeted and untargeted individuals.

Reinforcement and diffusion effects on voter participation are, however, quite different from ATEs, as they are all negative. This holds for different measures of connectedness and for both voter turnout and our behavioral measure of political participation. Negative reinforcement and diffusion effects on turnout are particularly strong for the hotline treatment. In contrast, peer effects on information and interest in politics are positive-and in-line with the average effects of the campaign.

We interpret these findings as consistent with a model of costly political participation. In this framework, voter turnout may be induced either by the probability of affecting the electoral process or by noninstrumental motivations like civic mindedness. By giving information about the credibility of the elections, the campaign intends to reassure voters about the integrity of the process. So doing, it may also raise civic mindedness. Both effects are conducive to increased turnout, in line with the average effects of the campaign. However, peer effects can induce a reduction in turnout if central voters realize that, because of the campaign, turnout will increase, and their vote becomes less essential in achieving a politically acceptable electoral result.

Our estimation of network effects in the context of a randomized field experiment relates to a recent body of work on the role of networks in aid interventions. Miguel and Kremer (2004) launched this literature by estimating the externalities of a deworming school-based program in Kenya. They estimated the impact of the treatment on control populations. Because their experimental design features program randomization at the school level, it does not allow for an experimental estimation of externalities within treated schools. More recently, Angelucci and De Giorgi (2009) extended the study of externalities to a conditional cash transfer program. By exploring a rich set of outcomes at the household level, they were able to draw some light into specific mechanisms of influence of unexposed households. However, these authors did not use explicit network variables. Still in the context of a conditional cash transfer program, Angelucci et al. (2010) introduced explicit interaction between households but focused on kinship links. Our analysis of kinship as a measure of social interaction is also related to Bandiera and Rasul (2006), who 
studied technology adoption in Mozambique in a nonexperimental setting. Baird et al. (2014) studied the design of experiments intended specifically to analyze spillover effects.

The experimental literature on voter mobilization was initiated by the studies of Alan Gerber and Donald Green. For instance, Gerber and Green (2000) studied the impact of a leaflet get-out-the-vote campaign in the United States. Dale and Strauss (2009) introduced text messaging in American get-out-the-vote campaigns and provided evidence that short message service (SMS) reminders increased the likelihood of voting. The studies by Nickerson (2008), Fafchamps and Vicente (2013), and Gine and Mansuri (2011) relate closely to our paper as they analyze peer effects of voter mobilization interventions. The first looked at a door-to-door get-out-the-vote campaign in the United States to identify peer effects in two-member households. The second followed a campaign against political violence in Nigeria to identify reinforcement- and diffusion-network effects. The third assessed the impact of a voter awareness campaign on female turnout in Pakistan; peer effects were estimated using geographical distance and friendship.

The paper is organized as follows: In Section II, we introduce the context of our experiment. The treatments are introduced in detail in Section III. In Section IV, we describe the data, including outcome and network variables. In Section $\mathrm{V}$, we report on average effects, including balance tests. Peer effects are presented in Section VI, together with robustness analysis. In Section VII, we discuss various possible interpretations of our peer-effect estimates and introduce additional tests. Section VIII concludes.

\section{Context}

Mozambique, a country with 22.4 million inhabitants, is one of the poorest countries in the world; with a gross domestic product (GDP) per capita of US $\$ 838$ in 2008, it ranks 161 st among 189 countries in terms of GDP per capita. Without prominent natural resources and with $81 \%$ of the population involved in agriculture, it is an aid-dependent country, with official aid assistance accounting for $22 \%$ of gross national income (GNI) in $2008{ }^{1}$

Mozambique became independent from Portugal in 1975, after which the independence movement Frente de Libertação de Moçambique (FRELIMO) led a single-party socialist regime. Beginning in 1977, Mozambique suffered a devastating civil war, fought between FRELIMO and Resistência Nacional

${ }^{1}$ These figures were taken from World Development Indicators 2009 (World Bank 2009) and CIA World Factbook 2010 (https://www.cia.gov/library/publications/download/download-2010/index .html). 
Moçambicana (RENAMO). RENAMO was supported by apartheid South Africa and, in the context of the cold war, by the United States. The civil war ended in 1992 with an agreement to hold multiparty elections. Since then, presidential and parliamentary elections have been held in Mozambique in 1994, 1999, 2004, 2009, 2014, and 2019. FRELIMO and its sponsored presidential candidates won all national elections, with RENAMO as the main contender. FRELIMO has increased its vote share over time, but voter turnout has decreased massively from $88 \%$ in 1994 to just 36\% in 2004 .

Armando Guebuza became FRELIMO's leader and president in 2004, succeeding Joaquim Chissano. Guebuza is a historical figure in FRELIMO. $\mathrm{He}$ fought against the Portuguese and was minister of the interior under Samora Machel. He became a wealthy and powerful businessman after the privatization of public companies in the 1990s. In the 2009 election that we study, he was running for reelection as president of the country. His main opponent, Afonso Dhlakama, had been the leader of RENAMO since 1984. He served as guerrilla leader during the civil war and had been RENAMO's presidential candidate in all national elections.

In this paper, we focus on the presidential, parliamentary, and provincial assembly elections of October 28, 2009. The 2009 elections were relatively calm, with FRELIMO and Guebuza expected to win. The elections were generally unproblematic, with national and international observers, considering that the 2009 election followed appropriate international standards, despite many small irregularities. Electoral results attributed $75 \%$ of the vote to Guebuza at the presidential elections and to FRELIMO at the parliamentary elections.

\section{Treatments}

The data in this paper come from a randomized controlled trial implemented around the time of the 2009 elections. Three treatments are investigated, all geared toward encouraging people to vote. The first treatment is the distribution of an independent newspaper providing electoral information; the second is a campaign to encourage voters to use an SMS-based hotline set up to report electoral problems; and the third is a civic education campaign that provides information about the electoral process and focuses on participation in the elections. The three interventions were designed and conducted with the institutional support and active collaboration of the newspaper @Verdade (http://www.verdade .co.mz/) and of a consortium of eight Mozambican NGOs under the name Observatório Eleitoral. For more details on these organizations, see Aker, Collier, and Vicente (2017). 
Voter education campaigns generally combine one or more of three elements: (i) information-providing information about the electoral process; (ii) participation-offering voters the opportunity to circulate their observations about the electoral process; and (iii) nudging - repeatedly reminding people to vote. ${ }^{2}$

The newspaper treatment combines all three elements: information, nudging, and participation. It centers on the distribution of the free newspaper @Verdade to experimental subjects in selected locations. None of the locations in the experiment had received the newspaper before. ${ }^{3}$ The editors of the newspaper took a strictly independent approach to the electoral process, focusing their message on electoral education. The newspaper was distributed to selected locations from the time of the baseline survey in September 2009 until the postelection survey of November 2009. Over this period, the newspaper included information designed and distributed by the electoral commission (Comissão Nacional de Eleições-Secretariado Técnico de Administração Eleitoral [CNE/ $\mathrm{STAE}]$ ). This information focused on the voting procedure during election day (see center panel of fig. A1 [figs. A1-A5 are available in the online appendix]). The newspaper also advertised a national hotline for reporting electoral problems (see right panel of fig. A1). For the distribution of the newspapers to treated villages, priority was given to targeted respondents. Five thousand copies of the newspaper were distributed each week, with a total of 125 for each location.

The hotline treatment emphasizes primarily information and participation. Two short-code phone numbers were contracted with the main cell phone operators in Mozambique (Mcel and Vodacom). These short codes were used to establish an SMS hotline inviting text messages reporting electoral problems. This hotline was branded with a different slogan and used different short codes from the newspaper hotline. During the baseline survey, we conducted a doorto-door campaign providing information on the hotline: we distributed 10,000 leaflets ( 250 per location) primarily directed at targeted respondents. These leaflets provided basic information about the hotline: short codes, the name of the sponsors, and examples or the format of reports to be sent. ${ }^{4}$ The leaflet is depicted in figure A2. Subjects were told that the contents of reports would be passed on to the media for dissemination and shared via SMS with all other targeted respondents in hotline-treatment locations. Before being disseminated, each report received was verified with local correspondents who were hired in each of

${ }^{2}$ See Dale and Strauss (2009) for an example of the effects of text messaging nudges on voter turnout in 2006 US elections. The effectiveness of nudging in other fields has also been documented (Thaler and Sunstein 2009; Pop-Eleches et al. 2011).

${ }^{3}$ Despite being the highest-circulation newspaper in Mozambique (with a minimum of 50,000 certified copies per week), the newspaper was only systematically distributed in the city of Maputo. As all newspaper locations lie outside the city of Maputo, they had never received the newspaper before. ${ }^{4}$ Specifically, ballot location name first and description of the problem second. 
the hotline-treatment locations. In addition to receiving these SMS reports throughout the electoral period, respondents in hotline areas were also sent daily SMS reminders about the existence of the hotline. These reminders were sent from 2 weeks prior to the election until election day.

The civic education treatment combines information and nudging elements. The intervention was initiated by a door-to-door campaign during the baseline survey, approximately a month before the elections. The treatment centers on the distribution of an extended version of the information provided by CNE/ STAE through the newspaper. It took the form of a leaflet designed and produced by CNE/STAE. A copy of the leaflet is displayed in figure A3. It explains in detail the voting procedure on election day. Ten thousand leaflets were distributed (i.e., 250 per location) primarily to targeted respondents. Moreover, for 2 weeks prior to the election, subjects in the civic education treatment received five daily text messages on the cell phone number that they provided during the baseline survey. The messages were about the importance of voter participation, as in a get-out-the-vote campaign. Within their 160-character limit, these messages also provided specific information about the electoral process, namely, the scheduled date, the type of election taking place, the presidential candidates, the parties running for parliament, voter confidentiality, and how to vote. ${ }^{5}$

All three treatments contain an information element encouraging subjects to vote. We therefore expect all of them to have a positive effect on turnout. The civic information treatment has the strongest nudging component. If this treatment has a particularly strong effect on turnout, it suggests that nudging can effectively induce people to vote. The hotline has the strongest participation element. A large treatment effect would suggest that turnout can be increased by encouraging voter participation in the electoral process.

\section{Data}

The project took place in four provinces: Cabo Delgado, Zambezia, Gaza, and Maputo Province. The sampling base is the 2004 electoral map of the country, and the enumeration area (EA) is the area covered by a polling station. Because the use of cell phones is central to all of our treatments, we eliminate from the sampling base all polling locations without cell phone coverage. For this purpose, we obtained detailed data from the two cell phone operators on the geographic locations of their antennae. The locations are then plotted on a map using their geographical coordinates, with a $5-\mathrm{km}$ coverage radius drawn around each. All

\footnotetext{
5 The experimental protocol for the three treatments was specifically that all targeted respondents were to be given the newspaper and the leaflets (for the hotline and civic education) and that no untargeted respondents were to be given these materials.
} 
polling stations outside the covered area are dropped from the sampling base. In $2009,60 \%$ of all polling stations in the country were covered by at least one operator.

From this sampling base, 161 polling locations were selected using two-stage clustered representative sampling-first on provinces and then on EAs. The number of registered voters per polling location is used as sampling weight. Because all registered voters in the sampling frame have the same probability of being sampled, the experimental locations are nationally representative of the voting population of Mozambique with mobile phone service. The allocation of locations to treatments and control follows a stratified randomization procedure (Bruhn and McKenzie 2009). First, clusters of four similar locations were formed in each province, with similarity based on geography. Within each cluster, locations were then randomly assigned to one of the three treatments or to control. During the baseline survey, in the event that we found no cell phone coverage in a selected location, we replaced it by the closest polling location with cell phone coverage. That happened in seven locations. ${ }^{6}$

In each of the EAs, we conducted two face-to-face household surveys, one before the election and treatment and one after. Sampling in each EA followed standard procedures for household representativeness ( $n$th house call by enumerators starting from the polling station, typically a school located at the center of the EA). Interviews at baseline were directed at the household head or his or her spouse. Interviews and subsequent treatment were conditional on whether respondents had access to a cell phone for receiving and sending calls and messages. Respondents who did not own a cell phone but had access to one via a neighbor or family member nearby are included in the study. The baseline survey includes 1,766 households/respondents, approximately 11 per EA. It was conducted from mid-September to mid-October 2009.

In treated EAs, of the average 11 households interviewed at the baseline, two were randomly selected not to receive the treatment themselves. They are called "untargeted." The other nine, the "targeted," were directly treated as described in the previous section. This randomization was implemented specifically to study diffusion effects among individuals in treated locations not directly targeted for treatment. ${ }^{7}$

The postelection survey started after the election results were announced in early November. It lasted for about the same duration as the baseline survey.

\footnotetext{
${ }^{6}$ One control substitute location was sampled but found not to be needed. It was added to our sample but has no impact on the results.

${ }^{7}$ Note that the relatively low number of untargeted respondents in treated locations has implications for relatively low statistical power to identify these diffusion effects.
} 
We attempted to reinterview all baseline respondents and reached 1,154 of them. ${ }^{8}$ To check that our results are not an artifact of selective attrition in the postelection survey, we verify, in the next section, whether observable characteristics vary systematically across treatments.

\section{A. Outcome Variables}

The outcomes of interest in this paper come mainly from survey and behavioral data collected at the individual level. Table A1 (tables A1-A10 are available in the online appendix) presents a summary of the survey outcome variables. These variables have been grouped into three sets: participation (turnout), information, and interest in the elections. We also report official voting results at polling stations.

We were particularly careful with the measurement of voter turnout, so we constructed six turnout measures. The first is self-reported turnout. The second is self-reported turnout adjusted by considering as nonvoters those who did not answer correctly questions regarding ballot papers and boxes. The third is an indicator of whether the respondent showed without hesitation his or her index finger to the enumerator when asked about which finger was marked after voting. Indeed, dipping the voter's finger in indelible ink was the method used to prevent people from voting multiple times. Turnout index 1 is a composite index incorporating information on how well the respondent answered the questions regarding the sequence of events on election day (including the question about which finger is inked). The answer to each question is coded according to how convincing the response is. Turnout index 2 is based on the subgroup of these questions that focuses on knowledge about the polling station. ${ }^{9}$ The last measure of turnout is an enumerator assessment on whether the respondent voted. The last three measures take values between 0 and 7 and are thus potentially more informative. To facilitate comparison with the other turnout measures, we normalize them by dividing by 7 , so they too range from 0 to $1 .{ }^{10}$ In the paper, we focus on index 2 , which is our preferred measure of individual turnout, because

\footnotetext{
8 The postelection survey takes place during the rainy season when most agricultural work (machambas) occurs. As agricultural plots tend to be located at a fair distance from home (Sheldon 1999; De Vletter 2001), agricultural workers often migrate during this season. In the survey, the most commonly reported reason for the absence of an adult dependent is agricultural work. Nonfarm work and traveling are also frequently reported as reasons for absence in Maputo Province, probably because it is more urbanized and offers more nonfarm employment opportunities (Cungara et al. 2011).

${ }^{9}$ These include correct answers regarding the number of ballot papers, whether there were photos of the candidates, the number of ballot boxes, whether the boxes were transparent, whether they were colored, and whether the respondent showed his or her index finger.

${ }^{10}$ The correlation between the different turnout measures ranges from 0.50 (between the adjusted turnout and the finger measure) to 0.98 (between the self-reported turnout and index 1).
} 
it includes the best factual adjustment to self-reported turnout allowed by our design. Evidence for other measures of individual turnout is presented in the online appendix. We note in passing that self-reported turnout is larger than all other turnout estimates. Overreporting is consistent with voting being regarded as a civic duty: if respondents saw voting as a repressed or reprehensible activity, we would expect the opposite pattern.

Our measure of electoral information is an index constructed from survey questions on the type of elections that took place in 2009, the duration of a presidential mandate, the lists of presidential candidates and parties running for the 2009 elections, and the meaning of electoral abstention. Answers given are marked as either correct or incorrect. Our measure of interest in the elections is constructed from Likert scale questions on the interest that the respondent had in the presidential election, the parliamentary election, the election to provincial assemblies, and public matters more generally. To facilitate analysis and interpretation, we combine these questions into two indexes: one for information about the elections and the other for interest in the political process. The indexes are constructed following the approach of Kling, Liebman, and Katz (2007): we normalize the survey indicators using $z$-scores, and we aggregate them using equally weighted averages of the normalized individual variables. The $z$-scores are calculated by subtracting the control group mean and dividing by the control group standard deviation. As a result, each component of the index has mean 0 and standard deviation 1 for the control group. ${ }^{11}$

A behavioral indicator of demand for political accountability, which we refer to as the "open letter," is obtained as follows: During the postelection survey, the enumeration team explained and distributed a leaflet to all survey respondents at all 161 experimental locations. The leaflet is depicted in figure A4. This leaflet invited the respondent to send an SMS message proposing policy priorities to the president-elect for his new mandate. We were clear in conveying the limited extent of the initiative (i.e., covering only a small number of experimental localities in Mozambique), and we promised that the contents of these messages would reach the president in person (i.e., through the newspaper @Verdade). As with the hotline, each message sent by an experimental subject had a small monetary cost. Sending the message therefore represents a costly action. The action of sending such a message is observable to us by matching the cell phone number of the message sender with that of the experimental subject recorded in the survey. We interpret sending such an open letter as an incentive-compatible indicator of demand for political accountability.

\footnotetext{
${ }^{11}$ As in Kling, Liebman, and Katz (2007), if an individual has a valid response to at least one component measure of an index, then we impute any missing values for other component measures at the random assignment group mean for the corresponding time period.
} 
Official voting results at the level of the polling station were made available by the electoral commission of Mozambique. Polling stations are easily matched with the EAs in our experiment, because, as mentioned earlier, EAs are based on the polling stations themselves. We focus on the main results of the 2009 elections: the presidential and parliamentary elections.

\section{B. Network Variables}

We collected three measures of social and geographical centrality. The first two are based on degree centrality in social networks. ${ }^{12}$ Let $i$ and $j$ be two individuals in the selected sample of targeted and untargeted participants in EA $v$ and let the EA sample size be $N_{v}+1$. We ask each $i$ whether he or she can identify $j$ by his or her name. If this is the case, we then ask $i$ whether he or she is related to $j$ and whether he or she talks to $j$ on a regular basis. ${ }^{13}$ We call the first type of social connection "kinship" and the second "chatting." Although kinship and chatting should in principle be objective facts on which both $i$ and $j$ agree, answers given by respondents $i$ and $j$ occasionally differ-probably because some links are more salient to the respondent. Because experimental subjects are more likely to be influenced by peers that they regard as kin or with whom they recall chatting, we define the social network of individual $i$ based only on the answers he or she gave.

Formally, let $g_{i j v}=1$ if $i$ reported a social connection to $j$, and 0 otherwise. The social network of $i$ is thus defined as $\left(1 / N_{v}\right) \sum_{j \neq i} g_{i j v}$, where $N_{v}$ is the number of respondents other than $i$ in EA $v$. Dividing by $N_{v}$ serves to net out slight differences in sample size across EAs. To illustrate, suppose that $g_{i j v}$ represents kinship. Then $\left(1 / N_{v}\right) \sum_{j \neq i} g_{i j v}$ is the proportion of participants in EA $v$ (other than $i$ ) that $i$ reports as kin. Similarly, if $g_{i j v}$ represents chatting, then $\left(1 / N_{v}\right) \sum_{j \neq i} g_{i j v}$ is the proportion of participants in EA $v$ (other than $i$ ) with whom $i$ reports talking on a regular basis.

The third variable captures how close $i$ is to other individuals in the sample. Because the sample is randomly selected, individuals who live close to the geographical center of the EA are closer to other participants than individuals located on the outskirts of the EA. Geographical centrality can thus be proxied by the

\footnotetext{
${ }^{12}$ Because we observe only a fraction of the chatting and kinship networks, we refrain from using other measures of centrality (e.g., Bonacich centrality) that are more sensitive to sample truncation bias (Chandrasekhar and Lewis 2012).

13 The first question asked was: "Are the following individuals relatives of yours, i.e., members of your family? Yes-No." The follow-up question was: "How frequently do you calmly chat about the day events with the following individuals or members of their households? Not at all, sometimes, or frequently." We considered existence of a link when the individual answered "sometimes" or "frequently."
} 
(negative of the) average distance from $i$ to others in the EA sample. Formally, let $g_{i j v}$ be the physical distance between individuals $i$ and $j$ in EA $v{ }^{14}$ The geographical centrality of $i$ is defined as $\left(-1 / N_{v}\right) \sum_{j \neq i} g_{i j v}$ : the higher (i.e., the less negative) this number is, the more central is $i$. With these definitions, social centrality increases in each of the measures and is normalized by the size of each EA sample.

\section{Average Treatment Effects}

We begin by summarizing the ATEs, some of which (though not all) already appear in Aker, Collier, and Vicente (2017). Peer effects are presented in the next section.

\section{A. Testing Strategy}

The combined (i.e., direct and indirect) average effect of the campaign is estimated as follows: Let $y_{i v}$ be a measure of electoral behavior, information, or interest for individual $i$ in village $v$. Let $T_{v}=1$ if village $v$ was treated, and 0 otherwise. Assuming treatment is randomly assigned, the homogeneous (average) effect of the campaign on treated individuals can be estimated using only targeted and control observations in a regression of the form

$$
y_{i v}=\alpha+\beta T_{v}+\varepsilon_{i v} .
$$

Coefficient $\beta$ is the ATE on $y_{i v}$, for example, electoral behavior, information, or interest. This regression can also be estimated with village and individual controls, to check the robustness of the findings.

We also estimate the average effect of the campaign on individuals in treated locations who were randomly selected not to be targeted by the campaign. We estimate this average effect using only untargeted and control observations in a regression of the same form showed above. Coefficient $\beta$ is then an estimate of the average diffusion effect of the campaign on the electoral behavior, information, or interest of untargeted individuals. Estimations of regression (1) constitute the focus of Aker, Collier, and Vicente (2017).

\section{B. Balance}

Before we show average treatment effects, we check balance by treatment on the baseline data. Table A2 presents descriptive statistics on demographic traits

\footnotetext{
${ }^{14}$ Each enumerator was asked to locate each respondent on an approximate EA map and to calculate the distance between interviews. See fig. A5 for an example. To evaluate the position of each respondent on the map, we construct up-and-down and left-and-right coordinates for each of them. The distance between each ij pair is then calculated from these coordinates. Because maps differ in scale, distances are rescaled to make them comparable across all locations. This is accomplished by using the subset of pairwise distances, i.e., the distance between interviews as reported by enumerators.
} 
of the baseline and postelection samples together with balance tests. We test balance relative to controls for each of the three treatments separately. Comparisons between treatment and control locations show that the samples are overall balanced. Regarding the sample of targeted respondents at the baseline, only three demographic characteristics out of 35 are significantly different at the $10 \%$ level. For untargeted individuals, the number of significant differences is reduced to two. The comparison between control and treated locations in the follow-up survey yields a similar pattern: in both samples of targeted and untargeted respondents, most household demographics are not significantly different. Panel attrition seems to have maintained comparability between the treatment groups in terms of observables. For EA characteristics, we also find only one statistically significant difference out of a list of ten variables across three treatments.

Social and geographical centrality variables are summarized in table A3. The social centrality variables, chatting and kinship, were collected during the postelection survey, and so we display only statistics for the postelection sample. ${ }^{15} \mathrm{We}$ do not observe any statistically significant differences across comparison groups.

Finally, we display averages for baseline voting variables at the polling-station level in table A4. These are voting records from the presidential and parliamentary elections of 2004. We do not observe any statistically significant differences across comparison groups. Individual outcome variables from the baseline survey are explored in full detail in Aker, Collier, and Vicente (2017). Because respondents were asked questions on politics after receiving either the leaflets or the newspaper, there could be differences across the targeted group due to conformity bias. No clear evidence of such effects is apparent in the data, however.

\section{Results}

We start by summarizing the regression results estimating the average effect of the campaign. We begin with political participation, which is the main objective of the campaign. Table 1 presents the average effect of the treatment on the voter turnout index and the sending of the open letter for targeted and untargeted individuals, respectively. The average effect on the remaining turnout measures is presented in table A5. Because, by design, turnout information can only be collected in the postelection survey, all regressions are estimated using only

\footnotetext{
${ }^{15}$ As this information could only be collected during the postelection survey, it raises the concern that the treatments may have affected the networks. The network measure "chatting" is the most vulnerable to this critique, as it is possible that the interventions trigger conversations between people who ordinarily would not chat. The network measures "kinship" and "geographical distance" are less likely to be susceptible to variations due to the interventions.
} 
TABLE 1

AVERAGE TREATMENT EFFECT ON POLITICAL PARTICIPATION

\begin{tabular}{|c|c|c|c|c|c|c|c|c|}
\hline & \multicolumn{4}{|c|}{ Targeted Individuals } & \multicolumn{4}{|c|}{ Untargeted Individuals } \\
\hline & \multicolumn{2}{|c|}{ Turnout Index } & \multicolumn{2}{|c|}{ Open Letter } & \multicolumn{2}{|c|}{ Turnout Index } & \multicolumn{2}{|c|}{ Open Letter } \\
\hline & (1) & (2) & (3) & (4) & (5) & (6) & (7) & (8) \\
\hline \multicolumn{9}{|l|}{ Treatment dummy: } \\
\hline Coefficient & $.076^{\star \star \star}$ & $.069^{\star \star \star}$ & -.033 & -.030 & $.088^{\star \star}$ & $.097^{\star \star \star}$ & .006 & .015 \\
\hline Standard error & $(.025)$ & $(.025)$ & $(.035)$ & $(.036)$ & $(.035)$ & $(.036)$ & $(.049)$ & $(.046)$ \\
\hline \multicolumn{9}{|l|}{ Newspaper dummy: } \\
\hline Coefficient & -.043 & -.032 & $.119^{\star \star \star}$ & $.110^{\star \star}$ & .002 & .024 & .051 & .038 \\
\hline Standard error & $(.030)$ & (.028) & $(.048)$ & $(.049)$ & $(.042)$ & $(.041)$ & $(.074)$ & $(.069)$ \\
\hline \multicolumn{9}{|l|}{ Civic education dummy: } \\
\hline Coefficient & -.028 & -.019 & $.079 *$ & $.078^{*}$ & -.026 & -.002 & .099 & .077 \\
\hline Standard error & $(.024)$ & $(.024)$ & $(.046)$ & $(.044)$ & $(.046)$ & $(.046)$ & $(.077)$ & $(.079)$ \\
\hline \multicolumn{9}{|l|}{ Province + randomization } \\
\hline cluster FE & Yes & Yes & Yes & Yes & Yes & Yes & Yes & Yes \\
\hline Controls & No & Yes & No & Yes & No & Yes & No & Yes \\
\hline \multicolumn{9}{|l|}{ Mean dependent variable } \\
\hline among controls & .757 & .756 & .153 & .151 & .757 & .756 & .153 & .151 \\
\hline Adjusted $R^{2}$ & .040 & .069 & .021 & .035 & .035 & .076 & .018 & .040 \\
\hline Number of observations & 953 & 943 & 973 & 962 & 437 & 430 & 449 & 441 \\
\hline
\end{tabular}

Note. Regressions in cols. 1-4 include observations for targeted (in treated locations) and control respondents. Regressions in cols. 5-8 include observations for untargeted (in treated locations) and control respondents. All regressions are ordinary least squares, use only second-round data, and include fixed effects (FE) for randomization cluster. In the second column of each outcome, we also control for demographic characteristics (sex, age, single, divorced, Protestant, retail informal sector, commerce, professional, teacher, domestic worker, household has enough food, owned house, Chitsua ethnic group, Lomue language, time living in the enumeration area [EA]), and EA characteristics (has a post office, has a health center). Standard errors are clustered at the EA level.

* Significant at $10 \%$.

** Significant at $5 \%$.

$\star \star \star$ Significant at $1 \%$.

postelection data. For each measure, we present one regression with province dummies and another with additional location and individual controls. All regressions control for randomization group dummies, and standard errors are clustered at the EA level.

The average value of the outcome variables for control individuals is reported in table 1 . According to our turnout index, $76 \%$ of control respondents are estimated to have voted in the 2009 election. This figure is higher than the 2009 national turnout average of $45 \%$. The difference is attributable to the fact that our respondents include only household heads or the spouses of household heads. Turnout among adult dependents is notoriously lower (Vaz 2013). Regarding the open letter, $15.3 \%$ of control individuals sent an SMS to the president through our project.

We see from table 1 that the average treatment effect of the campaign on turnout is statistically significant for both targeted and untargeted individuals. Given that the participation rate is already high among control respondents, the 
magnitude of the effect is large: between +6.9 and +9.7 percentage points, depending on the regression. If we estimate a pooled regression with targeted and untargeted subjects, we find no significant difference in average treatment effect ( $p$-values of .785 and .817). Among targeted individuals, the average treatment effects of the newspaper and civic education treatments are smaller in magnitude but not significantly so. There is also no statistical difference with untargeted individuals.

For the open letter, we find an increase in the probability of sending a message to the president for subjects in the newspaper and civic education treatments only. The magnitude of the effect is large: +11.0 and +7.8 percentage points, respectively, from a base of $15.1 \%$. The increase is statistically significant for targeted individuals, but we cannot reject the hypothesis that untargeted individuals exhibit a similar increase. There is no significant effect for the hotline treatment, possibly because subjects in that treatment already have an opportunity to express themselves via SMS.

Next, we turn to the average treatment effect on information and interest in politics. Because in both cases the dependent variable is a normalized index with mean zero and unitary variance among controls, coefficients are measured in standard deviation units of the underlying index. The results are displayed in table 2. As anticipated given the informational nature of the campaign, we find a significant positive treatment effect on the ability of targeted and untargeted respondents to answer basic questions about the elections. The effect is large in magnitude: it ranges between 0.16 and 0.19 standard deviation units for the targeted and between 0.20 and 0.28 standard deviation units for the untargeted. Point estimates are in general lower for the newspaper and civic education treatments, but the difference with the hotline treatment is never statistically significant. Regarding the effect of treatment on interest in politics, we find nonnegligible positive point estimates for both targeted and untargeted individuals. But only one of these point estimates is (marginally) significant.

Finally, we summarize in table 3 the average treatment effect on actual electoral outcomes from official polling station records (see Aker, Collier, and Vicente 2017). All treatments have a strong and significant positive effect on voter turnout. This effect ranges between 5.1 percentage points for the presidential election and 5.4 percentage points for the parliamentary election, with hardly any difference across treatments. On voting patterns, we find positive point estimates on voting for the incumbent president (Guebuza) and party (FRELIMO) and negative point estimates on voting for the main challenger candidate (Dhlakama) and party (RENAMO). As seen in table 3, this is particularly true for the newspaper and civic education treatments. If we separately estimate the average treatment effect of the newspaper and civic education treatments, we find that the latter is 
TABLE 2

AVERAGE TREATMENT EFFECT ON ELECTORAL INFORMATION AND INTEREST

\begin{tabular}{|c|c|c|c|c|c|c|c|c|}
\hline & \multicolumn{4}{|c|}{ Targeted Individuals } & \multicolumn{4}{|c|}{ Untargeted Individuals } \\
\hline & \multicolumn{2}{|c|}{$\begin{array}{l}\text { Basic Electoral } \\
\text { Information }\end{array}$} & \multicolumn{2}{|c|}{$\begin{array}{l}\text { Interest in } \\
\text { Elections }\end{array}$} & \multicolumn{2}{|c|}{$\begin{array}{l}\text { Basic Electoral } \\
\text { Information }\end{array}$} & \multicolumn{2}{|c|}{$\begin{array}{l}\text { Interest in } \\
\text { Elections }\end{array}$} \\
\hline & (1) & (2) & (3) & (4) & (5) & (6) & (7) & (8) \\
\hline \multicolumn{9}{|l|}{ Treatment dummy: } \\
\hline Coefficient & $.161^{\star \star \star}$ & $.186^{\star \star \star}$ & $.123^{\star}$ & .096 & $.198^{\star \star}$ & $.283^{\star \star \star}$ & .087 & .043 \\
\hline Standard error & $(.061)$ & $(.056)$ & $(.073)$ & $(.070)$ & $(.085)$ & $(.081)$ & $(.104)$ & (.106) \\
\hline \multicolumn{9}{|l|}{ Newspaper dummy: } \\
\hline Coefficient & -.020 & .005 & -.123 & -.116 & -.068 & -.099 & -.083 & -.114 \\
\hline Standard error & (.059) & $(.051)$ & (.079) & $(.076)$ & $(.109)$ & $(.101)$ & $(.164)$ & $(.171)$ \\
\hline \multicolumn{9}{|l|}{ Civic education dummy: } \\
\hline Coefficient & -.086 & -.004 & -.032 & .000 & -.076 & -.107 & -.087 & -.132 \\
\hline Standard error & $(.055)$ & $(.050)$ & $(.066)$ & $(.065)$ & $(.113)$ & $(.100)$ & $(.153)$ & (.149) \\
\hline \multicolumn{9}{|l|}{ Province + randomization } \\
\hline cluster FE & Yes & Yes & Yes & Yes & Yes & Yes & Yes & Yes \\
\hline Controls & No & Yes & No & Yes & No & Yes & No & Yes \\
\hline \multicolumn{9}{|l|}{ Mean dependent variable } \\
\hline among controls & .000 & .000 & -.000 & .006 & .000 & .000 & -.000 & .006 \\
\hline Adjusted $R^{2}$ & .095 & .264 & .125 & .159 & .076 & .300 & .176 & .205 \\
\hline Number of observations & 976 & 965 & 976 & 965 & 453 & 445 & 454 & 446 \\
\hline
\end{tabular}

Note. Regressions in cols. 1-4 include observations for targeted (in treated locations) and control respondents; regressions in cols. 5-8 include observations for untargeted (in treated locations) and control respondents. All regressions are ordinary least squares and use only second-round data. The dependent variables are indexes standardized to have mean 0 and variance 1. All regressions include fixed effects (FE) for randomization clusters. In the second column for each outcome, we control for demographic characteristics (sex, age, single, divorced, Protestant, retail informal sector, commerce, professional, teacher, domestic worker, household has enough food, owned house, Chitsua ethnic group, Lomue language, time living in the enumeration area $[E A]$ ), and EA characteristics (has a post office, has a health center). Standard errors are clustered at the EA level.

* Significant at $10 \%$.

** Significant at $5 \%$.

$\star \star \star$ Significant at $1 \%$.

statistically significant in all four voting regressions. The effect is large: it increases the score of FRELIMO and the incumbent president by 3.3 and 4.1 percentage points, respectively, and reduces votes for RENAMO and its presidential candidate by 3.4 and 2.8 percentage points, respectively.

To summarize, the campaign improved basic information about the electoral process and increased voter turnout — which was its objective-but it also benefited the incumbent and hurt the chances of the main challenger, significantly so for the civic education treatment.

\section{Peer Effects}

\section{A. Testing Strategy}

Drawing inspiration from Fafchamps and Vicente (2013), who analyze the peer effects of a campaign against electoral violence in Nigeria, we now investigate the role that peer effects played in the average treatment effects reported so far. 
TABLE 3

AVERAGE TREATMENT EFFECT ON OFFICIAL ELECTORAL RESULTS AT THE BALLOT-STATION LEVEL

\begin{tabular}{|c|c|c|c|c|c|c|}
\hline & \multicolumn{3}{|c|}{ Presidential Elections } & \multicolumn{3}{|c|}{ Parliamentary Elections } \\
\hline & $\begin{array}{l}\text { Turnout } \\
\text { (1) }\end{array}$ & $\begin{array}{c}\text { Votes for } \\
\text { Guebuza (\%) } \\
\text { (2) }\end{array}$ & $\begin{array}{c}\text { Votes for } \\
\text { Dhlakama (\%) } \\
\text { (3) }\end{array}$ & $\begin{array}{l}\text { Turnout } \\
\text { (4) }\end{array}$ & $\begin{array}{c}\text { Votes for } \\
\text { FRELIMO (\%) } \\
\text { (5) }\end{array}$ & $\begin{array}{c}\text { Votes for } \\
\text { RENAMO (\%) } \\
\text { (6) }\end{array}$ \\
\hline \multicolumn{7}{|l|}{ Treatment dummy: } \\
\hline Coefficient & $.051^{\star \star}$ & .019 & -.010 & $.054^{\star \star}$ & .017 & -.012 \\
\hline Standard error & $(.024)$ & $(.020)$ & $(.015)$ & $(.025)$ & $(.020)$ & $(.015)$ \\
\hline \multicolumn{7}{|l|}{ Newspaper dummy: } \\
\hline Coefficient & .001 & .021 & -.007 & -.000 & .018 & -.009 \\
\hline Standard error & $(.025)$ & $(.020)$ & $(.016)$ & $(.025)$ & $(.020)$ & $(.015)$ \\
\hline \multicolumn{7}{|l|}{ Civic education dummy: } \\
\hline Coefficient & -.002 & .022 & -.019 & -.006 & .015 & -.022 \\
\hline Standard error & $(.025)$ & $(.020)$ & $(.015)$ & $(.025)$ & $(.020)$ & $(.015)$ \\
\hline \multicolumn{7}{|l|}{ Province + randomization } \\
\hline cluster FE & Yes & Yes & Yes & Yes & Yes & Yes \\
\hline \multicolumn{7}{|l|}{ Mean dependent variable } \\
\hline among controls & .440 & .723 & .114 & .438 & .722 & .136 \\
\hline Adjusted $R^{2}$ & .412 & .691 & .610 & .393 & .701 & .670 \\
\hline Number of observations & 161 & 161 & 161 & 161 & 161 & 161 \\
\hline
\end{tabular}

Note. Observations include ballot stations in control and treated locations. All regressions are ordinary least squares. We control for enumeration area characteristics and province dummies. Standard errors are robust. FRELIMO = Frente de Libertação de Moçambique; RENAMO = Resistência Nacional Moçambicana; $F E=$ fixed effects.

** Significant at $5 \%$.

We first examine whether the effect of the campaign is stronger for targeted individuals who are socially or geographically close to other individuals in treated EAs. We estimate a reinforcement effect model of the form

$$
y_{i v}=\alpha+\beta T_{v}+\delta \frac{1}{N_{v}} \sum_{j \neq i} g_{i j v}+\gamma T_{v} \frac{1}{N_{v}} \sum_{j \neq i} g_{i j v}+\varepsilon_{i v},
$$

for which we use observations from targeted and control individuals only, that is, excluding untargeted individuals living in treated EAs. Regressor $\left(1 / N_{v}\right) \sum_{j \neq i} g_{i j v}$ is included as the control variable to capture the effect that network centrality has on $y_{i v}$ in the absence of treatment: coefficient $\delta$ measures the predictive effect of social or geographical centrality on $y_{i v}$. The main coefficient of interest is $\gamma \cdot{ }^{16} \mathrm{It}$

\footnotetext{
${ }^{16}$ As is well known, when estimating regression in eq. (2), the coefficient of the treatment variable $\beta$ is mechanically affected when we add any regressor interacted with treatment $T_{v}$. To ensure comparability with ATE estimates reported earlier, we express $\left(1 / N_{v}\right) \sum_{j \neq i} g_{i j v}$ in deviation from its sample mean. This method leaves $\gamma$ unaffected but ensures that $\beta$ still estimates the ATE. This approach is followed throughout this section, i.e., all regressors interacted with $T_{v}$ are always demeaned.
} 
captures how the effect of a treatment varies with social or geographical proximity to others in the same EA. ${ }^{17}$

We also investigate the presence of diffusion effects using the same specification but comparing untargeted to control individuals only, that is, excluding targeted individuals living in treated EAs. Interpretation is similar to that of reinforcement effects.

Based on earlier studies, we expect that $\gamma>0$ : social links and geographical proximity are anticipated to magnify the effect of treatment, for example, because the information content of treatment spreads more readily to central nodes and thus leads to a stronger impact of treatment. However, we cannot rule out a priori that $\gamma<0$, which would imply that peer effects are strategic substitutes rather than strategic complements. In this case, the treatment increases the outcome variable $y_{i v}$ (as shown in tables 1,2 ) but less so for more central individuals. This could arise if behavior $y_{i v}$ is beneficial for the group but individually costly and central individuals free ride on the effect that treatment has on others. We revisit this point in more detail later.

We use ordinary least squares in all our main regressions. Because the data we use are stratified by EA, we allow for within-group dependence by clustering standard errors at the EA level.

\section{B. Peer Effects on Political Participation}

We first apply the above testing strategy to our main focus of interest, namely, political participation measured by the turnout index and the open letter. Results are shown in table 4. We employ the three centrality variables introduced earlier: chatting, kinship, and geographic proximity. Estimated reinforcement effects are displayed in columns 1-3, while network diffusion effects are displayed in columns 4-6. We control for randomization group dummies, provincial dummies, EA characteristics, and individual controls. The main focus is on the $\delta$ and $\gamma$ coefficients in specification (2).

Regarding $\delta$, we note that more central individuals have a higher turnout propensity in control EAs: estimated coefficients for $\left(1 / N_{v}\right) \sum_{j \neq i} g_{i j v}$ are strongly positive. This is not only strong when using chatting and kinship as the centrality measure but also when using geographical proximity. This means that, without treatment, individuals who are more central in their community are more likely to vote. From these results alone, we cannot tell whether centrality causes people to be more civic minded-for example, because of social pressure or internalized

\footnotetext{
${ }^{17}$ In the event that $\gamma=0$, we cannot rule out the possibility that social network effects are so strong as to spread evenly to all individuals in treated villages, in which case proximity to treated individuals does not matter.
} 
TABLE 4

NETWORK EFFECTS ON TURNOUT INDEX

\begin{tabular}{|c|c|c|c|c|c|c|}
\hline & \multicolumn{3}{|c|}{ Targeted Individuals } & \multicolumn{3}{|c|}{ Untargeted Individuals } \\
\hline & $\begin{array}{l}\text { Chatting } \\
\text { (1) }\end{array}$ & $\begin{array}{l}\text { Kinship } \\
\text { (2) }\end{array}$ & $\begin{array}{c}\text { Proximity } \\
\text { (3) }\end{array}$ & $\begin{array}{l}\text { Chatting } \\
\text { (4) }\end{array}$ & $\begin{array}{c}\text { Kinship } \\
\text { (5) }\end{array}$ & $\begin{array}{c}\text { Proximity } \\
\text { (6) }\end{array}$ \\
\hline \multicolumn{7}{|l|}{ Treatment dummy: } \\
\hline Coefficient & $.072^{\star \star \star}$ & $.068^{\star \star \star}$ & $.069^{\star \star *}$ & $.101^{\star \star \star}$ & $.103^{\star \star \star}$ & $.092^{\star \star \star}$ \\
\hline Standard error & $(.025)$ & $(.025)$ & $(.027)$ & $(.037)$ & $(.037)$ & $(.035)$ \\
\hline \multicolumn{7}{|l|}{ Newspaper dummy: } \\
\hline Coefficient & -.029 & -.032 & -.046 & .024 & .019 & .022 \\
\hline Standard error & $(.028)$ & $(.028)$ & $(.031)$ & $(.042)$ & $(.042)$ & $(.040)$ \\
\hline \multicolumn{7}{|l|}{ Civic education dummy: } \\
\hline Coefficient & -.019 & -.020 & -.017 & .003 & .002 & -.027 \\
\hline Standard error & $(.025)$ & $(.025)$ & $(.028)$ & $(.045)$ & $(.044)$ & $(.045)$ \\
\hline \multicolumn{7}{|l|}{ Network variable: } \\
\hline Coefficient & $.255^{\star \star \star}$ & $.187^{\star \star}$ & .051 & $.245^{\star \star \star}$ & $.191^{\star \star}$ & $.070^{\star}$ \\
\hline Standard error & $(.079)$ & $(.081)$ & $(.031)$ & $(.071)$ & $(.076)$ & $(.040)$ \\
\hline \multicolumn{7}{|l|}{ Network $\times$ treatment: } \\
\hline Coefficient & $-.220^{\star \star}$ & $-.232^{\star \star}$ & -.045 & $-.363^{\star \star \star}$ & $-.344^{\star \star}$ & -.057 \\
\hline Standard error & $(.105)$ & $(.106)$ & $(.037)$ & $(.124)$ & $(.143)$ & $(.057)$ \\
\hline \multicolumn{7}{|l|}{ Network $\times$ newspaper: } \\
\hline Coefficient & .088 & .078 & -.017 & .150 & .149 & -.066 \\
\hline Standard error & $(.094)$ & $(.109)$ & $(.038)$ & $(.131)$ & $(.175)$ & $(.067)$ \\
\hline \multicolumn{7}{|l|}{ Network $\times$ civic education: } \\
\hline Coefficient & .080 & .037 & -.008 & .221 & $.453^{\star \star}$ & .033 \\
\hline Standard error & $(.106)$ & $(.107)$ & $(.025)$ & $(.152)$ & $(.182)$ & $(.060)$ \\
\hline \multicolumn{7}{|l|}{ Province + randomization } \\
\hline cluster FE & Yes & Yes & Yes & Yes & Yes & Yes \\
\hline Control variables & Yes & Yes & Yes & Yes & Yes & Yes \\
\hline \multicolumn{7}{|c|}{ Magnitude of network effects: ${ }^{a}$} \\
\hline Treatment & $-.049^{\star \star}$ & $-.027^{\star \star}$ & -.055 & $-.080^{\star \star \star}$ & $-.037^{\star \star}$ & -.067 \\
\hline Newspaper & .019 & .009 & -.020 & .033 & .016 & -.078 \\
\hline Civic education & .018 & .004 & -.010 & .048 & $.048^{\star \star}$ & .039 \\
\hline \multicolumn{7}{|l|}{ Mean dependent variable } \\
\hline among controls & .756 & .756 & .755 & .756 & .756 & .755 \\
\hline Adjusted $R^{2}$ & .080 & .069 & .073 & .089 & .078 & .082 \\
\hline Number of observations & 943 & 943 & 800 & 430 & 430 & 364 \\
\hline
\end{tabular}

Note. Regressions in cols. 1-3 include observations for targeted (in treated locations) and control respondents; regressions in cols. 4-6 include observations for untargeted (in treated locations) and control respondents. All regressions are ordinary least squares and use only second-round data. In addition to fixed effects (FE) for randomization clusters, we control for demographic characteristics (sex, age, single, divorced, Protestant, retail informal sector, commerce, professional, teacher, domestic worker, household has enough food, owned house, Chitsua ethnic group, Lomue language, time living in the enumeration area [EA]), EA characteristics (has a post office, has a health center), and province dummies. Standard errors are clustered at the EA level.

a For chatting and kinship, the reported network effect is the difference in average treatment effect between an individual with an average-sized network and an individual with no network at all. For geographical proximity, the reported network effect is the difference in average treatment effect between an individual with maximum (i.e., zero) proximity and an individual with average proximity.

* Significant at $10 \%$.

** Significant at $5 \%$.

$\star \star \star$ Significant at $1 \%$.

This content downloaded from 163.001.203.194 on January 29, 2020 06:59:20 AM

All use subject to University of Chicago Press Terms and Conditions (http://www.journals.uchicago.edu/t-and-c). 
norms - or whether more civic-minded people become more central—for example, because they are more sociable.

Turning to the interaction coefficients $\gamma$, we find that they are negative for the targeted and untargeted individuals and for all centrality measures, though only statistically significant for chatting and kinship. Negative peer effects are particularly strong for the hotline treatment, less so for the civic education and newspaper treatments.

To get a sense of the magnitude of peer effects, we calculate in table 4 the difference in predicted turnout between a treated subject with the average value of $\left(1 / N_{v}\right) \sum_{j \neq i} g_{i j v}$ and one either very central or not central at all, depending on the type of network. More specifically, for chatting and kinship, the comparison is with a treated subject with no connections, meaning $g_{i j v}=0$ for all $j$. A negative value means that moving from no connections to average centrality decreases the probability of voting induced by treatment. For geographical proximity, the comparison is between a hypothetical treated subject at distance 0 to others in the EA (i.e., most central) and a treated subject at the average distance. A negative value indicates that moving from being at the average distance from others to being maximally central reduces the probability of voting induced by treatment. The $p$-values are the same as those for the interaction coefficients.

We see that the magnitude of peer effects is large: relative to a hypothetical targeted subject with no peers, the effect of treatment on the turnout of a targeted subject with the average social network is 4.9 and 2.7 percentage point smaller for the chatting and kinship networks, respectively. This is equivalent to a shrinkage of the average treatment effect by $68 \%$ and $40 \%$, respectively. For untargeted subjects, the reduction in treatment effect is even larger. With geographical proximity, point estimates are different in size, but the proximity variable takes a wider range of values. If we look at the bottom of table 4, we find a large reduction in treatment effect between an individual with average centrality and maximally central individual. Although this reduction is not statistically significant for the hotline treatment, it is significant for the newspaper treatment among the untargeted. These results show that the ATE hides large variation across subjects depending on their geographical and network centrality: more central individuals experience a much smaller — and occasionally negative - effect of treatment on their propensity to vote. Similar results are obtained if we use alternative turnout measures. Detailed results are presented in table A6. Significant effects are all negative. ${ }^{18}$ In table A6b, we perform the same calculations regarding the magnitude of the network effects that we did in table 4 . They confirm that the magnitude of the network effects is large relative to the ATE.

\footnotetext{
${ }^{18}$ We also estimated ATE for the samples of targeted and untargeted individuals split into the $40 \%$ above the mean centrality and the $60 \%$ below the mean centrality. The findings described here are confirmed.
} 
Our preferred explanation for the negative network effects is free riding through pivotal reasoning: more central individuals are in a better position to realize, due to their centrality in the local network, that others are more likely to vote because of the campaign. They may also realize that the gap between the incumbent and other candidates is likely to increase. Hence their own electoral participation is less necessary to achieve a sufficient win gap to remain in the good favors of the government. Hence the likelihood that they turn out to vote decreases. We explore this—and other-explanations for negative peer effects more in detail in the final section of this paper.

Results for the open letter are displayed in table 5 . As in table 1 we find no peer effect of the hotline treatment on sending the open letter-probably for the same reason; namely, the ability of the hotline participants to send SMS messages to others serves as a substitute for an SMS message to the president. If we examine each treatment separately, however, we find that when we use chatting or kinship as a measure of social proximity, reinforcement and diffusion effects are negative and occasionally statistically significant for the civic education treatment. Here, too, the magnitude of this effects is large relative to the ATE. For instance, a subject targeted by the civic education treatment is $0.8+2.3=3.1$ percentage points less likely to send the open letter if he or she has the average kinship network than if he or she has no kinship network at all. For untargeted subjects, the reduction is $12.0-2.6=9.4$ percentage points. The potential explanation may be the same as for voter turnout: individuals with a large network realize that others will send an open letter as a result of treatment and feel that their participation is less essential.

\section{Peer Effects on Information and Interest in Politics}

We now seek to identify the channels through which the treatments affected political participation. We have already noted that the treatments had a direct positive effect on information about elections among targeted and untargeted individuals. But we could not find a statistically significant treatment effect on interest in politics. We now examine reinforcement and diffusion effects on information and interest in politics. We want to know whether information and interest are transmitted socially or geographically and, if yes, whether the effects are negative, as was the case for political participation. Regression model (2) is the same as before. All regressions are estimated using postelection data. Once again, we control for randomization cluster fixed effects, provincial dummies, EA characteristics, and individual characteristics.

Table 6 shows the results for information about the elections. We find large positive peer effects on the targeted, but only one is statistically significant (kinship). Unlike in the case of political participation, we do not see significant negative network effects, and the largest of these effects in absolute value 
TABLE 5

NETWORK EFFECTS ON POSTING THE OPEN LETTER

\begin{tabular}{|c|c|c|c|c|c|c|}
\hline & \multicolumn{3}{|c|}{ Targeted Individuals } & \multicolumn{3}{|c|}{ Untargeted Individuals } \\
\hline & $\begin{array}{l}\text { Chatting } \\
\text { (1) }\end{array}$ & $\begin{array}{l}\text { Kinship } \\
\text { (2) }\end{array}$ & $\begin{array}{l}\text { Proximity } \\
\text { (3) }\end{array}$ & $\begin{array}{l}\text { Chatting } \\
\text { (4) }\end{array}$ & $\begin{array}{l}\text { Kinship } \\
\text { (5) }\end{array}$ & $\begin{array}{c}\text { Proximity } \\
\text { (6) }\end{array}$ \\
\hline \multicolumn{7}{|l|}{ Treatment dummy: } \\
\hline Coefficient & -.030 & -.032 & -.022 & .011 & .001 & -.019 \\
\hline Standard error & $(.036)$ & (.037) & $(.039)$ & $(.048)$ & (.049) & $(.051)$ \\
\hline \multicolumn{7}{|l|}{ Newspaper dummy: } \\
\hline Coefficient & $.109^{\star \star}$ & $.110^{\star \star}$ & $.103^{\star \star}$ & .043 & .063 & .052 \\
\hline Standard error & $(.048)$ & (.049) & $(.051)$ & $(.071)$ & $(.073)$ & $(.070)$ \\
\hline \multicolumn{7}{|l|}{ Civic education dummy: } \\
\hline Coefficient & $.079 *$ & $.078^{\star}$ & .071 & .076 & .071 & .127 \\
\hline Standard error & $(.044)$ & $(.044)$ & $(.048)$ & $(.079)$ & $(.075)$ & $(.092)$ \\
\hline \multicolumn{7}{|l|}{ Network: } \\
\hline Coefficient & -.012 & .026 & .013 & .044 & .089 & $.079 * \star$ \\
\hline Standard error & $(.118)$ & $(.150)$ & $(.034)$ & $(.111)$ & $(.148)$ & $(.037)$ \\
\hline \multicolumn{7}{|l|}{ Network $\times$ treatment: } \\
\hline Coefficient & .150 & -.066 & .027 & .083 & .240 & .034 \\
\hline Standard error & $(.158)$ & $(.219)$ & $(.043)$ & $(.223)$ & $(.249)$ & $(.066)$ \\
\hline \multicolumn{7}{|l|}{ Network $\times$ newspaper: } \\
\hline Coefficient & -.163 & .022 & -.031 & .082 & .058 & .063 \\
\hline Standard error & $(.156)$ & $(.201)$ & $(.060)$ & $(.297)$ & $(.473)$ & $(.094)$ \\
\hline \multicolumn{7}{|l|}{ Network $\times$ civic education: } \\
\hline Coefficient & $-.254^{\star}$ & -.196 & .039 & -.413 & $-1.096^{\star \star \star}$ & -.051 \\
\hline Standard error & $(.140)$ & $(.176)$ & $(.047)$ & $(.263)$ & $(.369)$ & $(.128)$ \\
\hline \multicolumn{7}{|l|}{ Province + randomization } \\
\hline cluster FE & Yes & Yes & Yes & Yes & Yes & Yes \\
\hline Controls & Yes & Yes & Yes & Yes & Yes & Yes \\
\hline \multicolumn{7}{|c|}{ Magnitude of network effects: ${ }^{a}$} \\
\hline Treatment & .033 & -.008 & .032 & .018 & .026 & .040 \\
\hline Newspaper & -.036 & .003 & -.038 & .018 & .006 & .075 \\
\hline Civic education & $-.056^{\star}$ & -.023 & .047 & -.091 & 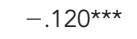 & -.061 \\
\hline \multicolumn{7}{|l|}{ Mean dependent variable } \\
\hline among controls & .151 & .151 & .158 & .151 & .151 & .158 \\
\hline Adjusted $R^{2}$ & .034 & .034 & .037 & .038 & .049 & .043 \\
\hline Number of observations & 962 & 962 & 817 & 441 & 441 & 373 \\
\hline
\end{tabular}

Note. Regressions in cols. 1-3 include observations for targeted (in treated locations) and control respondents; regressions in cols. 4-6 include observations for untargeted (in treated locations) and control respondents. All regressions are ordinary least squares and use only second-round data. We control for demographic characteristics (sex, age, single, divorced, Protestant, retail informal sector, commerce, professional, teacher, domestic worker, household has enough food, owned house, Chitsua ethnic group, Lomue language, time living in the enumeration area [EA]), EA characteristics (has a post office, has a health center), and province dummies. Standard errors are clustered at the EA level. FE $=$ fixed effects.

a For chatting and kinship, the reported network effect is the difference in average treatment effect between an individual with an average-sized network and an individual with no network at all. For geographical proximity, the reported network effect is the difference in average treatment effect between an individual with maximum (i.e., zero) proximity and an individual with average proximity.

* Significant at $10 \%$.

** Significant at $5 \%$.

$\star \star \star$ Significant at $1 \%$.

This content downloaded from 163.001.203.194 on January 29, 2020 06:59:20 AM

All use subject to University of Chicago Press Terms and Conditions (http://www.journals.uchicago.edu/t-and-c). 
TABLE 6

NETWORK EFFECTS ON THE ELECTORAL INFORMATION INDEX

\begin{tabular}{|c|c|c|c|c|c|c|}
\hline & \multicolumn{3}{|c|}{ Targeted Individuals } & \multicolumn{3}{|c|}{ Untargeted Individuals } \\
\hline & $\begin{array}{l}\text { Chatting } \\
\text { (1) }\end{array}$ & $\begin{array}{l}\text { Kinship } \\
\text { (2) }\end{array}$ & $\begin{array}{l}\text { Proximity } \\
\text { (3) }\end{array}$ & $\begin{array}{l}\text { Chatting } \\
\text { (4) }\end{array}$ & $\begin{array}{c}\text { Kinship } \\
(5)\end{array}$ & $\begin{array}{c}\text { Proximity } \\
\text { (6) }\end{array}$ \\
\hline \multicolumn{7}{|l|}{ Treatment dummy: } \\
\hline Coefficient & $.186^{\star \star \star}$ & $.188^{\star \star \star}$ & $.144^{\star \star}$ & $.297^{\star \star \star}$ & $.298^{\star \star \star}$ & $.257^{\star \star \star}$ \\
\hline Standard error & $(.055)$ & $(.055)$ & (.059) & $(.078)$ & $(.080)$ & (.089) \\
\hline \multicolumn{7}{|l|}{ Newspaper dummy: } \\
\hline Coefficient & .007 & .006 & .018 & -.111 & -.120 & -.066 \\
\hline Standard error & $(.052)$ & $(.051)$ & $(.051)$ & $(.100)$ & $(.102)$ & $(.114)$ \\
\hline \multicolumn{7}{|l|}{ Civic education dummy: } \\
\hline Coefficient & -.003 & -.002 & .013 & -.113 & -.111 & -.065 \\
\hline Standard error & $(.050)$ & $(.050)$ & $(.053)$ & (.098) & $(.100)$ & $(.106)$ \\
\hline \multicolumn{7}{|l|}{ Network: } \\
\hline Coefficient & -.098 & $-.394^{\star}$ & -.000 & -.044 & -.382 & .021 \\
\hline Standard error & $(.196)$ & $(.234)$ & $(.062)$ & $(.222)$ & (.234) & $(.069)$ \\
\hline \multicolumn{7}{|l|}{ Network $\times$ treatment: } \\
\hline Coefficient & .124 & $.484^{\star}$ & .092 & -.283 & -.003 & .079 \\
\hline Standard error & $(.255)$ & $(.290)$ & $(.075)$ & $(.407)$ & $(.415)$ & $(.125)$ \\
\hline \multicolumn{7}{|l|}{ Network $\times$ newspaper: } \\
\hline Coefficient & .132 & .090 & $-.144^{\star \star}$ & .294 & .183 & -.126 \\
\hline Standard error & $(.242)$ & $(.291)$ & $(.071)$ & $(.438)$ & $(.607)$ & $(.175)$ \\
\hline \multicolumn{7}{|l|}{ Network $\times$ civic education: } \\
\hline Coefficient & -.098 & $-.391^{\star}$ & $-.118^{\star}$ & .604 & $.818^{*}$ & -.173 \\
\hline Standard error & $(.203)$ & (.218) & $(.062)$ & $(.443)$ & $(.463)$ & $(.157)$ \\
\hline \multicolumn{7}{|l|}{ Province + randomization } \\
\hline cluster FE & Yes & Yes & Yes & Yes & Yes & Yes \\
\hline Controls & Yes & Yes & Yes & Yes & Yes & Yes \\
\hline \multicolumn{7}{|c|}{ Magnitude of network effects: ${ }^{a}$} \\
\hline Treatment & .027 & $.056^{\star}$ & .113 & -.063 & .000 & .093 \\
\hline Newspaper & .029 & .010 & $-.176^{\star \star}$ & .065 & .020 & -.149 \\
\hline Civic education & -.022 & $-.045^{\star}$ & $-.143^{\star}$ & .133 & $.089 *$ & -.205 \\
\hline \multicolumn{7}{|l|}{ Mean dependent variable } \\
\hline among controls & .000 & .000 & .009 & .000 & .000 & .009 \\
\hline Adjusted $R^{2}$ & .262 & .268 & .271 & .295 & .302 & .297 \\
\hline Number of observations & 965 & 965 & 820 & 445 & 445 & 377 \\
\hline
\end{tabular}

Note. Regressions in cols. 1-3 include observations for targeted (in treated locations) and control respondents; regressions in cols. 4-5 include observations for untargeted (in treated locations) and control respondents. All regressions are ordinary least squares and use only second-round data. We control for demographic characteristics (sex, age, single, divorced, Protestant, retail informal sector, commerce, professional, teacher, domestic worker, household has enough food, owned house, Chitsua ethnic group, Lomue language, time living in the enumeration area [EA]), EA characteristics (has a post office, has a health center), and province dummies. Standard errors are clustered at the EA level. FE $=$ fixed effects.

a For chatting and kinship, the reported network effect is the difference in average treatment effect between an individual with an average-sized network and an individual with no network at all. For geographical proximity, the reported network effect is the difference in average treatment effect between an individual with maximum (i.e., zero) proximity and an individual with average proximity.

* Significant at $10 \%$.

** Significant at $5 \%$.

$\star \star \star$ Significant at $1 \%$.

This content downloaded from 163.001.203.194 on January 29, 2020 06:59:20 AM

All use subject to University of Chicago Press Terms and Conditions (http://www.journals.uchicago.edu/t-and-c). 
is positive. Nonetheless, there is also a great deal of variation in peer effects across treatments and centrality measures, and some of these differences are statistically significant, so we should be careful not to overgeneralize.

Results for interest in politics are presented in table 7 . We find large positive peer effects on the targeted and untargeted for at least some of the treatments. The most robust peer effects are found for the newspaper treatment. Results indicate that chatting, kinship, and geographical proximity are all channels for reinforcement and diffusion effects. When estimated individually, almost all peer effects of the newspaper treatment are statistically significant, a majority of which is at the $1 \%$ level. As for tables 4-6, we report in table 7 estimates of the magnitude of network effects. For the newspaper treatment, we see that, relative to someone with no chatting links, a subject with an average chatting centrality is $0.118+0.089=0.207$ (reinforcement) or $0.017+0.279=0.296$ (diffusion) standard deviation units more interested in elections. For kinship, the corresponding figures are 0.111 and 0.184 . The success of the newspaper in raising interest in the elections suggests that the free copies of @Verdade that we left in the treated villages found their way into multiple hands. We find lower reinforcement effects for the hotline and civic education treatments, which by nature are more targeted toward individual subjects.

To summarize, direct treatment effects and network effects on information and interest in elections are generally positive-although the direct treatment effects on interest in politics and the network effects on information about politics are not statistically significant. The findings suggest that interest in politics is transmitted across networks, possibly because transmission of the newspaper across peers does not entail large costs.

\section{Robustness Checks}

Although balance tests do not indicate that panel attrition significantly affects the comparability of treatment and control groups, we nevertheless test how sensitive our results are to missing postelection observations. We use the multipleimputation method to replace the missing values of outcome and control variables; and we reestimate the average and network effects on political participation using the full sample of baseline respondents. Multivariate normal regressions are used. ${ }^{19}$ In the imputation model, we include the variables that we use in our empirical analysis, plus other characteristics of the household and of the respondents,

\footnotetext{
${ }^{19}$ Given than most variables are categorical, we considered using chained equations. However, it was very difficult to find a model that would include all the relevant variables and converge. Schafer and Graham (2002) argue that normal imputation models have a good performance for linear regressions, even when the variables are nonnormal.
} 
TABLE 7

NETWORK EFFECTS ON THE INDEX OF INTEREST IN ELECTIONS

\begin{tabular}{|c|c|c|c|c|c|c|}
\hline & \multicolumn{3}{|c|}{ Targeted Individuals } & \multicolumn{3}{|c|}{ Untargeted Individuals } \\
\hline & $\begin{array}{l}\text { Chatting } \\
\text { (1) }\end{array}$ & $\begin{array}{l}\text { Kinship } \\
\text { (2) }\end{array}$ & $\begin{array}{c}\text { Proximity } \\
\text { (3) }\end{array}$ & $\begin{array}{l}\text { Chatting } \\
\text { (4) }\end{array}$ & $\begin{array}{c}\text { Kinship } \\
\text { (5) }\end{array}$ & $\begin{array}{c}\text { Proximity } \\
\text { (6) }\end{array}$ \\
\hline \multicolumn{7}{|l|}{ Treatment dummy: } \\
\hline Coefficient & .105 & .100 & .118 & .056 & .055 & .063 \\
\hline Standard error & $(.069)$ & $(.068)$ & $(.079)$ & $(.102)$ & (.101) & $(.121)$ \\
\hline \multicolumn{7}{|l|}{ Newspaper dummy: } \\
\hline Coefficient & -.108 & -.114 & $-.145^{\star}$ & -.116 & -.084 & -.198 \\
\hline Standard error & $(.078)$ & $(.076)$ & $(.085)$ & (.165) & (.164) & (.187) \\
\hline \multicolumn{7}{|l|}{ Civic education dummy: } \\
\hline Coefficient & -.001 & .005 & .018 & -.131 & -.147 & -.064 \\
\hline Standard error & $(.066)$ & $(.065)$ & $(.072)$ & $(.145)$ & $(.154)$ & $(.167)$ \\
\hline \multicolumn{7}{|l|}{ Network: } \\
\hline Coefficient & -.225 & -.360 & $.158^{\star \star}$ & -.197 & -.138 & .089 \\
\hline Standard error & $(.170)$ & $(.252)$ & $(.069)$ & $(.173)$ & $(.313)$ & $(.074)$ \\
\hline \multicolumn{7}{|l|}{ Network $\times$ treatment: } \\
\hline Coefficient & $.539^{\star \star}$ & $.664^{\star}$ & -.096 & .077 & .057 & -.132 \\
\hline Standard error & $(.228)$ & $(.352)$ & $(.128)$ & $(.437)$ & $(.686)$ & $(.201)$ \\
\hline \multicolumn{7}{|l|}{ Network $\times$ newspaper: } \\
\hline Coefficient & .409 & .290 & -.052 & $1.267^{\star \star}$ & $1.640^{*}$ & $.502^{\star}$ \\
\hline Standard error & $(.291)$ & $(.416)$ & $(.136)$ & $(.592)$ & $(.851)$ & $(.270)$ \\
\hline \multicolumn{7}{|l|}{ Network $\times$ civic education: } \\
\hline Coefficient & -.011 & -.548 & -.090 & .610 & -.342 & .191 \\
\hline Standard error & $(.228)$ & $(.383)$ & $(.121)$ & $(.556)$ & $(.972)$ & $(.225)$ \\
\hline \multicolumn{7}{|l|}{ Province + randomization } \\
\hline cluster FE & Yes & Yes & Yes & Yes & Yes & Yes \\
\hline Controls & Yes & Yes & Yes & Yes & Yes & Yes \\
\hline \multicolumn{7}{|c|}{ Magnitude of network effects: ${ }^{a}$} \\
\hline Treatment & $.118^{\star \star}$ & $.077^{\star}$ & -.117 & .017 & .006 & -.155 \\
\hline Newspaper & .089 & .034 & -.064 & $.279^{\star \star}$ & $.178^{\star}$ & $.593^{\star}$ \\
\hline Civic education & -.002 & -.063 & -.110 & .134 & -.037 & .226 \\
\hline \multicolumn{7}{|l|}{ Mean dependent variable } \\
\hline among controls & .006 & .006 & -.011 & .006 & .006 & -.011 \\
\hline Adjusted $R^{2}$ & .169 & .164 & .141 & .222 & .219 & .233 \\
\hline Number of observations & 965 & 965 & 820 & 446 & 446 & 378 \\
\hline
\end{tabular}

Note. Regressions in cols. 1-3 include observations for targeted (in treated locations) and control respondents; regressions in cols. 4-6 include observations for untargeted (in treated locations) and control respondents. All regressions are ordinary least squares and use only second-round data. We control for demographic characteristics (sex, age, single, divorced, Protestant, retail informal sector, commerce, professional, teacher, domestic worker, household has enough food, owned house, Chitsua ethnic group, Lomue language, time living in the enumeration area $[E A]$ ), EA characteristics (has a post office, has a health center), and province dummies. Standard errors are clustered at the EA level. FE = fixed effects. a For chatting and kinship, the reported network effect is the difference in average treatment effect between an individual with an average-sized network and an individual with no network at all. For geographical proximity, the reported network effect is the difference in average treatment effect between an individual with maximum (i.e., zero) proximity and an individual with average proximity.

* Significant at $10 \%$.

** Significant at $5 \%$.

This content downloaded from 163.001.203.194 on January 29, 2020 06:59:20 AM

All use subject to University of Chicago Press Terms and Conditions (http://www.journals.uchicago.edu/t-and-c). 
characteristics of the EA, and interactions between the interventions and characteristics of the household and respondents.

Recalculated estimates of the ATEs on political participation are similar to the ones obtained earlier. In table A7, we present the average effect of each of the three treatments on the political participation of targeted respondents. This table is to be compared with table 1 . We find a very similar pattern of significant effects, particularly for the results on average diffusion among untargeted respondents.

For networks interacted with the treatment effects, the coefficients remain negative for most treatments and network measures. We find a similar pattern of significant results, although with a smaller magnitude. Table A8 displays the estimates of interaction effects on the turnout index variable using imputed data. Comparing these results with the ones observed in table 4, we see that almost all of the significant network effects remain, although they have smaller magnitudes. The same can be said when we estimate the interaction terms for other turnout measures using imputed data (table A9) and compare them to the original results (table A6). Overall, we conclude that using multiple imputation to correct for attrition corroborates our findings.

We also estimate two complementary models of the form

$y_{i v}=\alpha_{1}+\beta_{1} T_{v}+\delta_{1} \frac{1}{N_{v}^{\mathrm{TARG}}} \sum_{j \neq i ; j \in \mathrm{TARG}} g_{i j v}+\gamma_{1} T_{v} \frac{1}{N_{v}^{\mathrm{TARG}}} \sum_{j \neq i ; j \in \mathrm{TARG}} g_{i j v}+\varepsilon_{i v}$

and

$$
\begin{aligned}
y_{i v}= & \alpha_{2}+\beta_{2} T_{v}+\delta_{2} \frac{1}{N_{v}^{\mathrm{UNTARG}}} \sum_{j \neq i ; j \in \mathrm{UNTARG}} g_{i j v} \\
& +\gamma_{2} T_{v} \frac{1}{N_{v}^{\mathrm{UNTARG}}} \sum_{j \neq i ; j \in \mathrm{UNTARG}} g_{i j v}+\varepsilon_{i v},
\end{aligned}
$$

where TARG and UNTARG refer to targeted and untargeted groups of individuals. We apply the above regression models to both reinforcement and diffusion. If peer effects occur solely through proximity to targeted individuals, we should observe $\gamma_{1} \neq 0$ and $\gamma_{2}=0$. In this particular configuration, regression model (4) can then be seen as a falsification test of regression (3). In contrast, if $\gamma_{1}$ and $\gamma_{2}$ are similar in magnitude and significance, we should conclude that $\gamma_{1}$ and $\gamma_{2}$ capture systematic variation in the effect of treatment on central and noncentral individuals, irrespective of whether they are close to targeted or untargeted individuals.

Estimates for these models are presented in table A10. We do not find strong evidence that $\gamma_{1}$ and $\gamma_{2}$ coefficients vary systematically. If anything, we obtain many significant $\gamma_{2}$ estimates in spite of the fact that the number of untargeted 
individuals in each EA is much smaller than the number of targeted individuals - and hence power should be smaller in regression model (4). From this we conclude that the benchmark model we have estimated is the most informative for the data we have collected.

\section{Discussion}

To assess the external validity of our findings, we need some understanding of the channels by which treatments affect outcomes. To this purpose, we look for a coherent narrative that can account for the whole body of evidence that we have gathered, with a particular focus on turnout, which is our main outcome of interest. After a detailed examination of the evidence (presented in the appendix), one empirical finding stands out because it contradicts all standard models of political influence: negative reinforcement and diffusion effects could not arise if peer effects were due to either information diffusion, inflamed partisanship, or social pressure to vote. All these predict positive peer effects of treatment. To account for negative peer effects, a new conceptual framework is needed that can account for this finding. To this we now turn.

\section{A. Conceptual Framework}

To articulate and check the internal consistency of our proposed narrative, we introduce a model of voter participation combining several of the features discussed in the literature. The focus is on turnout. ${ }^{20} \mathrm{We}$ start by making sure that our model incorporates the implicit belief underlying our treatment, namely, that an educational campaign about elections raises the information level of voters. This affects their belief in the fairness and transparency of the electoral process, their interest in the voting process rises as a result, and people increase turnout to reflect their heightened level of information and interest. This causal chain naturally extends to the diffusion of treatment to individuals not targeted by the campaign and for reinforcement effects among the targeted; that is, as information circulates among people, interest in elections rises, and turnout increases.

To formalize this general idea in a compact manner, we build on the numerous sources summarized by Dhillon and Peralta (2002) and Feddersen (2004). Let us assume that an individual $i$ decides a political participation vector $x_{i}$ (e.g., casting a vote, sending text messages with political content) to maximize a payoff function:

$$
\max _{x_{i}} E_{\Omega_{i}} U\left(G\left(x_{i}, x_{-i}\right), x_{i}\right)-C\left(x_{i}\right)
$$

\footnotetext{
${ }^{20}$ Other forms of political participation such as the open letter follow the same logic.
} 
where $G\left(x_{i}, x_{-i}\right)$ is the outcome of the electoral process, $x_{-i}$ is the combined action of individuals other than $i, \Omega$ denotes $i$ s information set, and $C\left(x_{i}\right)$ is the total material cost of the action for individual $i$ (e.g., transport cost, opportunity cost of time, cost of text messaging). To capture noninstrumental motivations, we allow $x_{i}$ to enter the function $U$ independently from the outcome of the voting process $G$.

The first-order condition

$$
E_{\Omega_{i}}\left[\frac{\partial U}{\partial G} \frac{\partial G}{\partial x_{i}}+\frac{\partial U}{\partial x_{i}}\right]=\frac{d C}{d x_{i}}
$$

illustrates how a voter education campaign can influence turnout. First, the campaign can change voters' information set $\Omega_{i}$. Distributing information about the electoral process may convince voters of the integrity of the electoral process, thereby raising $E_{\Omega_{i}}\left[(\partial U / \partial G)\left(\partial G / \partial x_{i}\right)\right]$. Second, the campaign may increase the noninstrumental motivation $\partial U / \partial x_{i}$, either through a support-your-team effect or by raising civic mindedness. All these effects increase voter participation.

Well-known conceptual difficulties arise when noninstrumental motivations are absent; namely, when $\left(\partial U / \partial x_{i}\right)=0$. Optimal turnout then requires $E_{\Omega_{i}}\left[(\partial U / \partial G)\left(\partial G / \partial x_{i}\right)\right]=d C / d x_{i}$. When a single vote has little effect on the electoral outcome, as is conceivable for large elections, then $\partial G\left(x_{i}, x_{-i}\right) / \partial x_{i}$ is small and voting is not individually rational, unless the marginal cost of participation is close to zero. This paradox dates back at least to Downs (1957). ${ }^{21}$ Introducing noninstrumental motives for voting alleviates the problem: the first-order condition $E_{\Omega_{i}}\left[\partial U / \partial x_{i}\right]=d C / d x_{i}$ can be satisfied for an interior $x_{i}$ even when $E_{\Omega_{i}}\left[(\partial U / \partial G)\left(\partial G / \partial x_{i}\right)\right]=0$.

The implicit assumption that motivates our treatments is that circulating information affects voters' information set $\Omega_{i}$ and, so doing, increases $E_{\Omega_{i}}\left[(\partial U / \partial G)\left(\partial G / \partial x_{i}\right)+\left(\partial U / \partial x_{i}\right)\right]$ and induces higher turnout. The model shows that information can increase turnout in two ways: first, by increasing the probability that is vote is pivotal $\left(E_{\Omega_{i}}\left[(\partial U / \partial G)\left(\partial G / \partial x_{i}\right)\right]\right)$ and, second,

${ }^{21}$ A lively debate has followed. Using a game-theoretic voting game with two candidates, Palfrey and Rosenthal (1983) find a high turnout equilibrium generated by a high probability of being pivotal. This stems from having nearly identical numbers of voters supporting each candidate. This result was short-lived: the same authors (Palfrey and Rosenthal 1985) demonstrate that the introduction of incomplete information and a large population eliminates the possibility that high turnout arises in equilibrium. Recently, Myatt (2015) recovered the idea that $\partial G\left(x_{i}, x_{-i}\right) / \partial x_{i}$ depends on the perceived competitiveness of the election. Myatt considers a two-candidate election in which there is aggregate uncertainty about the popularity of each candidate. Crucially, Myatt finds that turnout is high under reasonable conditions. 
by strengthening is noninstrumental motivation for voting $\left(E_{\Omega_{i}}\left[\partial U / \partial x_{i}\right]\right)$. The model also shows that more information can reduce turnout if it lowers the probability of being pivotal, that is, if it lowers $E_{\Omega_{i}}\left[(\partial U / \partial G)\left(\partial G / \partial x_{i}\right)\right]$. For instance, a citizen may decide not to vote if he or she learns that his or her preferred politician is guaranteed to be elected.

Being pivotal is usually understood as influencing who wins the election. This definition makes sense in advanced democracies. Voters in other countries may care about other electoral outcomes, such as the turnout or win gap. This is particularly true in electoral autocracies where the winner of the election is often known in advance and where a low turnout or win gap is seen as disapproving of the government. Political disapproval can be punished by various means, including a lower supply of local public goods. In such a political environment, being pivotal does not mean casting the ballot that determines who wins the election; it means bringing the turnout or win gap above the threshold below which the community faces reprisals. Some prima facie support for this approach can be found in our data: the treatment increased turnout by individuals who voted for the incumbent party (see table 3).

In the traditional meaning of "pivotal voter," the deciding ballot is a precisely defined concept; the only uncertainty is regarding whether $i$ 's vote is decisive. This limits the range of beliefs consistent with voting (e.g., Myatt 2015). In contrast, a pivot based on turnout or win gap is subject to additional uncertainty regarding the minimum level needed to avoid political reprisal. This implies that the proportion of voters who can rationally believe themselves to be pivotal is larger. The pivotal logic remains, however: $i$ is more (less) likely to vote if $i$ receives information that raises (lowers) the likelihood that his or her vote would be pivotal. ${ }^{22}$

Pivotal reasoning predicts that an information treatment changes the turnout level depending on location-specific beliefs about the turnout or win gap. In EAs where one party won the 2004 election by a large margin, voters may rationally expect the win gap to be large in 2009 as well-and thus may have a lower expectation of being pivotal. These beliefs are, of course, victim to a fallacy of composition, which some voters may realize as a consequence of treatment. We test this prediction in table 8 . Results reported in column 1 confirm that control EAs where the win gap was large in 2004 experience a significantly lower turnout in 2009. We also observe a significant positive interaction between the treatment

\footnotetext{
${ }^{22}$ The pivotal logic can take an instrumental interpretation at the individual level. But it can also work at the collective level: because reaching a target turnout or win gap generates a local public good, voting can be regarded as contributing to that public good. Social pressure can then be applied to induce individual contributions so that the collective target is reached.
} 
TABLE 8

TREATMENT EFFECT ON TURNOUT INDEX BY 2004 WIN GAP AND TURNOUT

\begin{tabular}{|c|c|c|}
\hline & $\begin{array}{c}\text { Win Gap } \\
\text { (1) }\end{array}$ & $\begin{array}{c}\text { Turnout } \\
\text { (2) }\end{array}$ \\
\hline \multicolumn{3}{|l|}{ Treatment: } \\
\hline Coefficient & $.074^{\star \star \star}$ & $.067^{* \star *}$ \\
\hline Standard error & $(.025)$ & $(.025)$ \\
\hline \multicolumn{3}{|l|}{ Newspaper: } \\
\hline Coefficient & -.031 & -.031 \\
\hline Standard error & $(.028)$ & $(.027)$ \\
\hline \multicolumn{3}{|l|}{ Civic education: } \\
\hline Coefficient & -.018 & -.022 \\
\hline Standard error & $(.025)$ & $(.024)$ \\
\hline \multicolumn{3}{|c|}{2004 turnout/win gap between FRELIMO and RENAMO: } \\
\hline Coefficient & $-.036^{\star}$ & -.172 \\
\hline Standard error & $(.021)$ & $(.133)$ \\
\hline \multicolumn{3}{|l|}{2004 win gap/turnout $\times$ treatment: } \\
\hline Coefficient & $.047^{\star}$ & .003 \\
\hline Standard error & $(.027)$ & $(.162)$ \\
\hline \multicolumn{3}{|l|}{2004 win gap/turnout $\times$ newspaper: } \\
\hline Coefficient & .010 & .272 \\
\hline Standard error & $(.028)$ & $(.208)$ \\
\hline \multicolumn{3}{|l|}{2004 win gap/turnout $\times$ civic education: } \\
\hline Coefficient & -.018 & .019 \\
\hline Standard error & $(.025)$ & $(.178)$ \\
\hline Province + randomization cluster FE & Yes & Yes \\
\hline Controls & Yes & Yes \\
\hline Mean dependent variable among controls & .756 & .756 \\
\hline Adjusted $R^{2}$ & .070 & .069 \\
\hline Number of observations & 943 & 943 \\
\hline
\end{tabular}

Note. Regressions include observations for targeted (in treated locations) and control respondents. All regressions are ordinary least squares and use only secondround data. We control for demographic characteristics (sex, age, single, divorced, Protestant, retail informal sector, commerce, professional, teacher, domestic worker, household has enough food, owned house, Chitsua ethnic group, Lomue language, time living in the enumeration area [EA]), EA characteristics (has a post office, has a health center), and province dummies. Standard errors are clustered at the EA level. The win gap is the difference in 2004 vote shares between the Frente de Libertação de Moçambique (Frelimo) and Resistência Nacional Moçambicana (Renamo) presidential candidates at the EA level. FE $=$ fixed effects.

* Significant at $10 \%$.

$\star \star \star$ Significant at $1 \%$.

and the 2004 win gap: the campaign reduces the drop in turnout relative to control locations in EAs with larger win gaps. Column 2 replaces the 2004 win gap with that year's voter turnout. The effect is not significant, suggesting that voters care mainly about the win gap.

Pivotal reasoning implies that an information treatment can affect people differently depending on how aware they are of others' turnout intentions. To illustrate, take $N+1$ voters arranged in a star-shaped network. The center of the star represents a subject who is more central in a social or geographical 
sense. Let us assume that each voter observes the voting intentions of his or her immediate neighbor. The star center thus observes the voting intentions of the $N$ other voters who, in contrast, only observe the intention of the star center. The impact of the treatments in this network (assuming for simplicity that all nodes are targeted) depends on whether each node believes itself to be pivotal. If the star center is more aware of the positive average effects of the campaign on the win gap, he or she is less likely than the spokes to consider him- or herself a pivotal voter. ${ }^{23}$ Hence free riding through pivotal reasoning implies that the treatment should result in a lower turnout propensity for the star center than for spoke voters.

\section{B. Empirical Verification}

This prediction is at prima facie consistent with our findings. In control EAs, subjects who are more central are more likely to vote-possibly because they realize that the large 2004 win gap has disincentivized spoke voters to turn out. This pattern is by and large reversed in treated EAs: treatment induces the average voter to turn up to vote, and possibly as a result, well-informed central subjects need not increase their own turnout as much as in control EAs.

Because we have information on voting by peers, we can directly investigate a key prediction of pivotal reasoning: citizens who realize many of their social or geographical neighbors are likely to vote may decide not to vote; namely, voting is a strategic substitute. Put differently, pivotal reasoning predicts a negative relationship between my decision to vote and turnout among my peers. It is important to realize that we are not trying to ascribe causality. We just test whether my turnout is negatively correlated with the turnout of my peers: If more of them turn up to vote, am I less likely to vote, and vice versa?

To investigate this possibility, we estimate a model of the form

$$
y_{i v v}=\alpha+\lambda \frac{1}{N_{v}} \sum_{j \neq i} g_{i j v} y_{j v}+\beta \frac{1}{N_{v}} \sum_{j \neq i} g_{i j v} T_{j v}+\delta \frac{1}{N_{v}} \sum_{j \neq i} g_{i j v v}+\mu_{v}+\varepsilon_{i v},
$$

where $y_{j v}$ is the turnout index of individual $j$ and $T_{j v}=1$ if peer $j$ was targeted for treatment. ${ }^{24}$ Regression (6) is estimated with EA fixed effects $\mu_{\nu}$ as well as

\footnotetext{
${ }^{23}$ This example can easily be generalized as follows. Let $N_{i v}$ be the subset of other voters that $i$ observes in village $v$ and $N_{-i v}$ be the rest. Let $T_{v}$ denote treatments as before. We have $x_{v}=\sum_{j \in N_{i v}} x_{j}+\sum_{j \in N_{-i}} x_{j}$ and $\partial E_{\Omega_{i}}\left[x_{v}\right] / \partial T_{v}=N_{i v} / N_{v} E_{\Omega_{i}}\left[\partial x_{j} / \partial T_{v}\right]$ as the observed change in behavior. Because the effect of treatment on turnout is positive, i.e., $\partial x_{j} / \partial T_{v}>0$, it follows that individuals with a larger $N_{i v}$ increase their expectation $E_{\Omega_{i}}\left[x_{v}\right]$ more than people with a small $N_{i v}$. Hence they are less likely to see themselves are pivotal and thus to vote.

${ }^{24}$ Given our experimental design, it is in principle possible to estimate endogenous and exogenous peer effects simultaneously by using the treatment of $i$ s neighbors as an instrument for the behavior
} 
individual controls. EA treatment effects are omitted because they are subsumed in the EA fixed effects. We estimate regression (6) using targeted and untargeted respondents, with a dummy for untargeted respondents. Pivotal reasoning/strategic substitution in turnout predict $\lambda<0$ : Conditional on my peers having been targeted for treatment, my own turnout is negatively correlated with my peers' turnout because, if they vote, I do not need to vote and vice versa. In contrast, strategic complements in turnout (e.g., due to information diffusion, inflamed partisanship, or social pressure to vote) predict $\lambda>0$. In either case, we are not interpreting $\lambda$ as causal; we regard it as a correlation in behavior predicted to arise in equilibrium.

Results are presented in table 9. In columns 1 and 2, the regressor of interest is the average turnout index of my peers - the more of them who voted, the larger is the regressor. In column 3, the regressor of interest is the average turnout of other villagers, weighted by their distance to me. We see that in all three cases, individual $i$ is less likely to vote if more of his or her neighbors voted. The correlation is large in magnitude and statistically significant. This evidence suggests that the voting choices of social and geographical neighbors are strategic substitutes. Because this prediction comes out of pivotal reasoning but not from other models of peer effects in voting decisions, the evidence presented in table 9 supports the idea that pivotal reasoning is behind the negative peer effects of treatment found in our experiment.

\section{Pivotal Reasoning versus Saturation}

Before concluding, we perform one last test of the relevance of the interpretation we have offered for our findings. Demonstrating that treatment can reduce turnout among central subjects due to pivotal reasoning is not the same as showing that it is behind our result. There may be other explanations. One possibility we would like to rule out is that the negative coefficient of the $T_{v}\left(1 / N_{v}\right) \sum_{j \neq i} g_{i j v}$ term reflects a voter saturation effect rather than pivotal reasoning.

Because individuals with a larger social network vote with a high probability on average, it may be more difficult to further increase their likelihood of voting. This, and not pivotal reasoning, could explain why the effect of the treatment on these individuals is weaker than on individuals with a smaller social network. To show this formally, let $P_{i v}$ represent individual is propensity to vote in village $v$ in the absence of treatment. We now assume that voter turnout among the targeted follows

of $i$ 's neighbors (see Bramoullé, Djebbari, and Fortin 2009). We tried this approach as well. Unfortunately, the small sample size in each location precluded this approach: because of overlap in distance-2 neighborhoods, there is not enough variation in the instrument to identify endogenous and exogenous effects separately. 
TABLE 9

NETWORK EFFECTS ON TURNOUT INDEX, CONTROLLING FOR TURNOUT BY PEERS

\begin{tabular}{|c|c|c|c|}
\hline & $\begin{array}{l}\text { Chatting } \\
\text { (1) }\end{array}$ & $\begin{array}{c}\text { Kinship } \\
\text { (2) }\end{array}$ & $\begin{array}{c}\text { Proximity } \\
\text { (3) }\end{array}$ \\
\hline \multicolumn{4}{|l|}{ Average turnout of peers: } \\
\hline Coefficient & $-.858^{\star \star \star}$ & $-1.086^{\star \star \star}$ & $-1.042^{\star \star \star}$ \\
\hline Standard error & $(.288)$ & $(.187)$ & $(.259)$ \\
\hline \multicolumn{4}{|c|}{ Percentage of my peers who were treated: } \\
\hline Coefficient & -.129 & -.091 & $-.250^{\star \star}$ \\
\hline Standard error & $(.089)$ & $(.080)$ & $(.098)$ \\
\hline \multicolumn{4}{|c|}{ Percentage of EA sample who are my peers: } \\
\hline Coefficient & $.806^{\star \star \star}$ & $1.050^{\star \star \star}$ & $-.490 \star \star$ \\
\hline Standard error & $(.224)$ & $(.156)$ & $(.195)$ \\
\hline \multicolumn{4}{|l|}{ Untargeted dummy: } \\
\hline Coefficient & .025 & .026 & .017 \\
\hline Standard error & $(.021)$ & $(.022)$ & $(.019)$ \\
\hline \multicolumn{4}{|l|}{ Intercept: } \\
\hline Coefficient & $.744^{\star \star \star}$ & $.733^{\star \star \star}$ & $.806^{\star \star \star}$ \\
\hline Standard error & $(.039)$ & $(.038)$ & $(.050)$ \\
\hline Individuals controls & Yes & Yes & Yes \\
\hline EA fixed effects & Yes & Yes & Yes \\
\hline Adjusted $R^{2}$ & .034 & .058 & .175 \\
\hline Number of observations & 1,106 & 1,106 & 1,106 \\
\hline
\end{tabular}

Note. Regressions include observations on respondents in control and treated villages. All regressions are ordinary least squares and use second-round data. We control for enumeration area (EA) fixed effects as well as demographic characteristics (sex, age, single, divorced, Protestant, retail informal sector, commerce, professional, teacher, domestic worker, household has enough food, owned house, Chitsua ethnic group, Lomue language, time living in the EA). Standard errors are clustered at the EA level.

$\star *$ Significant at $5 \%$.

$\star \star \star$ Significant at $1 \%$.

$$
y_{i v}=P_{i v}+\beta T_{v}+\gamma T_{v} \frac{1}{N_{v}} \sum_{j \neq i} g_{i j v}+\pi P_{i v} T_{v}+\varepsilon_{i v},
$$

where $\gamma$ captures pivotal reasoning as before and a significantly negative $\pi$ coefficient indicates voter saturation. A bias in the previous estimation of $\gamma$ arises if $P_{i v}$ is correlated with network size $\left(1 / N_{v}\right) \sum_{j \neq i} g_{i j v}$. To demonstrate this, let $P_{i v}=\alpha+\delta\left(1 / N_{v}\right) \sum_{j \neq i} g_{i j v}$ and replace $P_{i v}$ in (7):

$y_{i v}=\alpha+\delta \frac{1}{N_{v}} \sum_{j \neq i} g_{i j}+(\beta+\alpha \pi) T_{v}+(\gamma+\delta \pi) T_{v} \frac{1}{N_{v}} \sum_{j \neq i} g_{i j v}+\varepsilon_{i v}$.

Comparing regressions (8) with (2), it is immediately apparent that voter saturation-a negative $\pi$ - can be misinterpreted as pivotal reasoning — a negative $\gamma$-when estimating regression (2).

The solution we propose is to estimate $\hat{P}_{i v}$ using individuals in untreated locations and use it as a control function to obtain separate estimates of $\gamma$ and $\pi$. We obtain $\hat{P}_{i v}$ using only control individuals by regressing turnout on network 
size $\left(1 / N_{v}\right) \sum_{j \neq i} g_{i j v}$, individual controls, province dummies, and EA characteristics. Because treatment is assigned randomly, $\hat{P}_{i v}$ is a consistent predictor of treated individuals' propensity to vote in the absence of treatment. We can also estimate the ATE $\hat{\beta}$ in the usual way, for example, as in table 1 . We then estimate regression (7) on targeted individuals using $\hat{P}_{i v}$ in lieu of $P_{i v}$ and $\hat{\beta}$ in lieu of $\beta$. Since by design $T_{i}=1$ for the targeted, the estimated regression boils down to

$$
y_{i v}-\hat{\beta}=(1+\pi) \hat{P}_{i v}+\gamma \frac{1}{N_{v}} \sum_{j \neq i} g_{i j v}+\varepsilon_{i v}{ }^{25}
$$

Voter saturation $\pi<0$ requires that the coefficient of $\hat{P}_{i}$ be less than 1. Coefficient $\gamma$ in regression (9) is estimated free of voter saturation bias. Note that regression (9) has no intercept, which in this case offers the advantage of minimizing attenuation bias due to prediction error in $\hat{P}_{i}$. Since regression (9) includes two predicted regressors, $\hat{P}_{i v}$ and $\hat{\beta}$, we rely on bootstrapping to obtain consistent standard errors. To cluster standard errors as the EA level, bootstrapping is conducted by sampling EAs with replacement to construct each simulated sample. Each bootstrap iteration first reestimates $\hat{P}_{i v}$ and $\hat{\beta}$ on the simulated data and then uses them to run (9) on that same data. Standard errors are obtained from the simulated distribution of $\pi$ and $\gamma$ across 500 bootstrap replications. Here we pool targeted and untargeted respondents to increase power.

Point estimates are presented in table 10, together with a test that the coefficient of $\hat{P}_{i v}$ is different from 1 . We see that, for the chatting and kinship networks, the coefficient of $\hat{P}_{i v}$ is marginally above 1 and is not significantly different from 1. The network coefficient $\gamma$ remains negative, even if it is not precisely identified. We can thus reject that saturation is behind negative peer effects. For proximity, the evidence shows that $\hat{\pi}$ is significantly less than 0 , supporting the idea that a saturation effect is present. However, the point estimate for $\gamma$ remains negative-and is statistically significant. In other words, even if our results are affected by a saturation effect when we use geographical proximity as network variable, network peer effects remain significantly negative even when we account for it. Overall, this evidence indicates that saturation is not the explanation for our results.

\section{Concluding Remarks}

Using a large-scale field experiment, we have investigated how voter education treatments affected political participation in the 2009 elections in Mozambique.

\footnotetext{
${ }^{25}$ It is easy to verify that including the control individuals as well does not affect the results, given the way $\hat{P}_{i}$ is constructed, so control individuals can be ignored.
} 
TABLE 10

TESTING FOR SATURATION

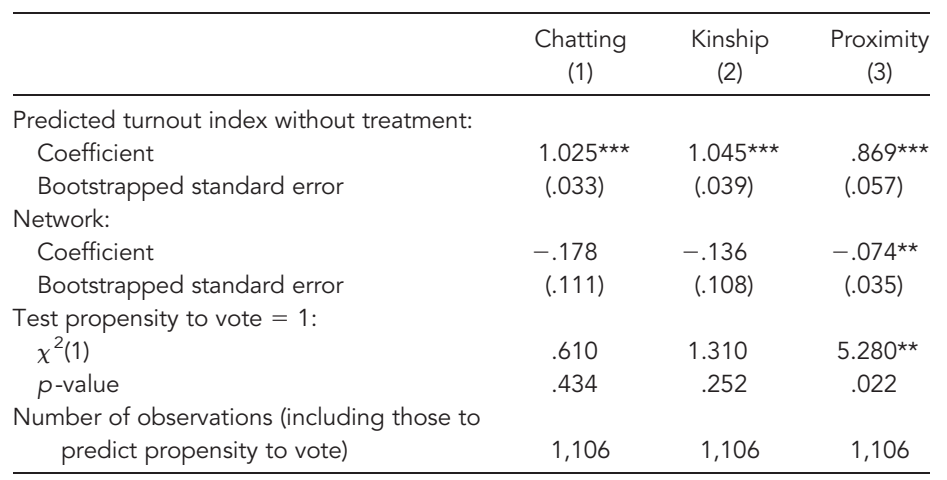

Note. Reported regressions include only observations from treated villages in the second-round data, including targeted and untargeted individuals. All regressions are ordinary least squares without constant term, and the dependent variable is the turnout index minus the average treatment effect (see text for details). Predicted propensity to vote in control villages is obtained by linearly regressing turnout index on network size, demographic characteristics (sex, age, single, divorced, Protestant, retail informal sector, commerce, professional, teacher, domestic worker, household has enough food, owned house, Chitsua ethnic group, Lomue language, time living in the enumeration area [EA]), EA characteristics (has a post office, has a health center), and province dummies. Since the predicted propensity to vote already captures the effect of these regressors on turnout, they are omitted from the above regressions. Standard errors (in parentheses) are obtained using bootstrapping to simulate the distribution of estimated coefficients resulting from this two-step approach. More specifically, we reestimate the predicting regression multiple times by sampling with replacement from the control observations. We do the same for the average treatment effect. For each set of predicted variables obtained in this manner, we reestimate the regression reported here by sampling with replacement from the treated population. Five hundred replications are used to produce the reported standard errors. To allow for interdependence of errors within EAs, resampling is done over EAs.

** Significant at $5 \%$.

$\star \star \star$ Significant at $1 \%$.

Three types of interventions were tested: (1) distribution of an independent newspaper, (2) access to a text-message hotline, and (3) a civic education campaign. The interventions are shown to increase voter turnout and the electoral knowledge of targeted and untargeted individuals in treated locations. Using several measures of network centrality based on social and geographical connectedness, we estimate reinforcement and diffusion network effects. We find that peer effects on political participation are consistently negative, which means that individuals with many connections to other surveyed subjects are less likely to vote than similar individuals with fewer connections. This is particularly clear for the hotline treatment. At the same time, interest in politics is positively transmitted across peers. 
We interpret these findings in the context of a voter participation framework in which voter education can affect information and interest in politics and hence change voter behavior. We argue that the sign of the network effects suggests free riding through pivotal reasoning: a smaller treatment effect on turnout among central individuals results from realizing that the campaign is driving more people to vote, making their own turnout less essential.

These results have implications for the design of voter education campaigns. Although social networks tend to magnify treatment effects on soft outcomes such as interest in elections, they can attenuate turnout by circulating information about voting intentions, thereby triggering free riding through pivotal reasoning.

\section{Appendix}

\section{Channels of Influence}

The purpose of this appendix is to discuss the different possible channels of influence that could explain our results. A first possible channel of influence is that credible information about the electoral process increases voter confidence and induces discouraged voters - namely, opposition supporters - to vote. If this were true, we would expect an increase in information and interest about the electoral process in treated enumeration areas, as well as a higher share of ballots going to the opposition. Because information often diffuses along social networks, we would also expect positive diffusion and reinforcement effects. ${ }^{26}$ Is this narrative supported by the empirical results? On the positive side, we find some (limited) effects of the treatments on information about voting and on in interest in elections. But if anything, the treatments have increased voting for the incumbent and reduced voting for the opposition, and the negative peer effects we document on turnout are hard to reconcile with this narrative.

A second possibility is that the treatments inflame partisan passions, and people vote to support their team. This channel of influence does not require that people become more knowledgeable about the details of the electoral process. Since people vote not so much to affect the electoral outcome but to show support for a party or candidate, it does not matter if they do not expect to be pivotal voters. We therefore expect treatments to induce high participation rates and, in a context dominated by the incumbent, more votes for the ruling party. Because this channel of influence relies on herding behavior, we expect to observe both diffusion and reinforcement effects. More of our findings are consistent with a support-your-team effect: namely, the limited effects

\footnotetext{
${ }^{26}$ See, e.g., Montgomery and Casterline (1996) on social learning.
} 
on interest about the elections and the clear average effect on turnout. Treatments increase voting for the dominant party, a finding that is difficult to reconcile with the idea that treatment reassured opposition voters to cast their vote. We also find that the hotline treatment has the strongest positive effect on turnout among targeted and untargeted individuals, perhaps because text messages about electoral abuse can be used to rally others. But the negative peer effects are again difficult to reconcile with this narrative.

A third possibility is that our treatments affect voting through social pressureeither directly through treatment nudging or indirectly through peer-to-peer reinforcement and diffusion effects. This channel is likely to be most relevant when the act of voting is seen as a civic duty. Civic education is expected to have the strongest direct treatment effect in this case because it is focused on nudging. If this is the channel through which treatments increase turnout, we do not necessarily expect treated individuals to be more knowledgeable about the electoral process or to be more interested in the electoral outcome. Some of our findings are consistent with this social pressure/civic duty interpretation, notably the robust direct effect of the civic education treatment on turnout. But, once again, negative peer effects are difficult to explain with this narrative.

\section{References}

Aker, J., P. Collier, and P. C. Vicente. 2017. "Is Information Power? Using Cell Phones and Free Newspapers during an Election in Mozambique.” Review of Economics and Statistics 99, no. 2:185-200.

Angelucci, M., and G. De Giorgi. 2009. "Indirect Effects of an Aid Program: How Do Cash Transfers Affect Ineligibles' Consumption?” American Economic Review 99, no. 1:486-508.

Angelucci, M., G. De Giorgi, M. Rangel, and I. Rasul. 2010. "Family Networks and School Enrollment: Evidence from a Randomized Social Experiment." Iournal of Public Economics 94, nos. 3-4:197-221.

Baird, S., J. A. Bohren, C. McIntosh, and B. Ozler. 2014. "Designing Experiments to Measure Spillover Effects.” PIER Working Paper no. 14-006, Penn Institute for Economic Research, Department of Economics, University of Pennsylvania, Philadelphia.

Bandiera, O., and I. Rasul. 2006. "Social Networks and Technology Adoption in Northern Mozambique.” Economic Iournal 116, no. 514:862-902.

Banerjee, A. V., S. Kumar, R. Pande, and F. Su. 2011. "Do Informed Voters Make Better Choices? Experimental Evidence from Urban India.” Mimeograph. Harvard University, Cambridge, MA.

Bramoullé, Y., H. Djebbari, and B. Fortin. 2009. "Identification of Peer Effects through Social Networks." Iournal of Econometrics 150, no. 1:41-55.

Bruhn, M., and D. McKenzie. 2009. "In Pursuit of Balance: Randomization in Practice in Development Field Experiments." American Economic Journal: Applied Economics 1 , no. 4:200-232. 
Chandrasekhar, A. G., and R. Lewis. 2012. "Econometrics of Sampled Networks." Mimeograph. Massachusetts Institute of Technology, Cambridge.

Collier, P., and P. C. Vicente. 2014. "Votes and Violence: Evidence from a Field Experiment in Nigeria." Economic Journal 124, no. 574:F327-F355.

Cungara, B., G. Fagilde, J. Garrett, R. N. Uaiene, and D. Headey. 2011. "Growth Without Change: The Elusiveness of Agricultural and Economics Transformation in Mozambique." Paper presented at the Dialogue on Promoting Agricultural Growth in Mozambique, Maputo, July 21.

Dale, A., and A. Strauss. 2009. "Don't Forget to Vote: Text Message Reminders as a Mobilization Tool." American Journal of Political Science 53, no. 4:787-804.

De Vletter, F. 2001. "Coping with Extreme Poverty through Traditional Skills: The Case of the Xirundzu Basket Makers of Mozambique.” ILO/SAMAT Discussion Paper no. 18, International Labour Organization, Southern African Multidisciplinary Advisory Team, Harare.

Dhillon, A., and S. Peralta. 2002. "Economic Theories of Voter Turnout." Economic Iournal 112:F332-F352.

Downs, Anthony. 1957. An Economic Theory of Democracy. New York: Harper \& Row.

Fafchamps, M., and P. C. Vicente. 2013. "Political Violence and Social Networks: Experimental Evidence from a Nigerian Election." Iournal of Development Economics 101:27-48.

Feddersen, T. 2004. "Rational Choice Theory and the Paradox of Not Voting." Iournal of Economic Perspectives 18, no. 1:99-112.

Fujiwara, V., and L. Wantchekon. 2013. "Can Informed Public Deliberation Overcome Clientelism? Experimental Evidence from Benin." American Economic Iournal: Applied Economics 5, no. 4:241-55.

Gerber, A., and D. Green. 2000. "The Effect of a Nonpartisan Get-Out-the-Vote Drive: An Experimental Study." Iournal of Politics 62:846-57.

Gine, X., and G. Mansuri. 2011. "Together We Will: Experimental Evidence on Female Voting Behavior in Pakistan.” Policy Research Working Paper no. 5692, World Bank, Washington, DC.

Kling, J. R., J. B. Liebman, and L. F. Katz. 2007. "Experimental Analysis of Neighborhood Effects." Econometrica 75, no. 1:83-119.

Miguel, E., and M. Kremer. 2004. "Worms: Identifying Impacts on Education and Health in the Presence of Treatment Externalities." Econometrica 72, no. 1:159-217.

Montgomery, M. R., and J. B. Casterline. 1996. "Social Learning, Social Influence, and New Models of Fertility." Population and Development Review 22 (supol.): 151-75.

Myatt, D. P. 2015. "A Theory of Voter Turnout." Mimeograph. London Business School, London.

Nickerson, D. W. 2008. "Is Voting Contagious? Evidence from Two Field Experiments." American Political Science Review 102, no. 1:49-57.

Palfrey, T., and H. Rosenthal. 1983. "A Strategic Calculus of Voting." Public Choice 41, no. 1:7-53.

. 1985. "Voter Participation and Strategic Uncertainty." American Political Science Review 79, no. 1:62-78. 
Pop-Eleches, C., H. Thirumurthy, J. P. Habyarimana, J. G. Zivin, M. P. Goldstein, D. De Walque, L. MacKeen, et al. 2011. "Mobile Phone Technologies Improve Adherence to Antiretroviral Treatment in a Resource-Limited Setting: A Randomized Controlled Trial of Text Message Reminders." AIDS 25:825-34.

Schafer, J. L., and J. W. Graham. 2002. "Missing Data: Our View of the State of the Art." Psycholooical Methods 7, no. 2:147-77.

Sheldon, K. 1999. "Machambas in the City: Urban Women and Agricultural Work in Mozambique.” Lusotopie 6, no. 6:121-40.

Thaler, R. H., and C. R. Sunstein. 2009. Nudge: Improving Decisions about Health, Wealth and Happiness. New York: Penguin.

Vaz, A. 2013. "Interpersonal Influence and Network Effects on Voting Behavior: Experimental Evidence from Mozambique." PhD diss., Oxford University, Oxford.

Vicente, P. C. 2014. "Is Vote-Buying Effective? Evidence from a Field Experiment in West Africa.” Economic Journal 124, no. 574:F356-F387.

Wantchekon, L. 2003. "Clientelism and Voting Behavior: Evidence from a Field Experiment in Benin." World Politics 15, no. 3:399-422.

World Bank. 2009. World Development Indicators 2009. Washington, DC: World Bank. https://openknowledge.worldbank.org/handle/10986/4367. 